\title{
El sueño dorado de Isabel II: Instauración y declive del Teatro de Palacio (1849-1851)
}

\author{
Sara Navarro Lalanda, Universidad Autónoma de Madrid, España, \\ España
}

Resumen: La presente investigación centra su interés en el estudio del Teatro de Palacio instaurado por Isabel II en 1849, fundamentalmente a través del análisis de fuentes hemerográficas inéditas; anuncios, ensayos y crónicas difundidas al público general que, complementadas con fuentes documentales tanto del Real Conservatorio Superior de Música de Madrid como del Archivo General de Palacio, nos permitirán profundizar en la infraestructura, intérpretes, representaciones y público de este "teatrino" real hasta su desaparición definitiva en 1851, en que los restos de los sueños de una reina que quiso vivir por encima de sus posibilidades serán trasladados a la institución pedagógica fundada por su madre, el Real Conservatorio de Música y Declamación María Cristina.

Palabras Clave: Teatro de Palacio, Isabel II, Real Cámara, Real Conservatorio de Música y Declamación María Cristina de Borbón

Abstract: This research focuses mainly on the study of the Palace Theatre founded by Isabella II in 1849, mostly through the analysis of several sources such as unpublished newspapers; advertisements, essays and chronicles disseminated to the general public, complemented by documentary sources from the Royal Conservatory of Music of Madrid as well as the General Archive of the Royal Palace, that will allow us to study the infrastructure, interpreters, and public performances of this royal "teatrino" in depth until his final closure in 1851. The remains of the institution dreamed by the queen, who wanted to live beyond her possibilities, were transferred to the educational institution founded by her mother, the Royal Conservatory of Music and Declamation Maria Cristina.

Keywords: Palace Theatre, Isabella II, Court, Royal Chamber, Royal Conservatory of Music and Declamation María Cristina de Borbón

Revista Internacional de Ciencias Humanas

Volumen 1, Número 2, http://lascienciashumanas.com, ISSN 2530-4526

(C) Global Knowledge Academics, Sara Navarro Lalanda, Todos los Derechos Reservados

Permisos: soporte@gkacademics.com

Republicado de Revista Internacional de Humanidades 1(2), 2012 (pp. 239-268) 


\section{A modo de introducción}

ESDE EL PUNTO de vista de la historiografía ${ }^{1}$, el presente estudio se centra en $\mathrm{D}$ el periodo moderado de reinado de Isabel $\mathrm{II}^{2}$. A fin de ubicar los gustos artísticos y musicales de esta reina que dan lugar a la creación del teatro de Palacio, hemos de partir de su contextualización como hija del rey absolutista, Fernando VII, y de María Cristina de Borbón, fundadora por real orden de 15 de julio de 1830 del Real Conservatorio de Música y Declamación que llevaría su nombre ${ }^{3}$.

La formación musical inculcada a las hijas de este matrimonio, la futura reina Isabel II y su hermana la infanta María Luisa Fernanda, tendría un importante componente musical, siendo sus preceptores desde su más tierna infancia Francisco Frontera de Valldemosa y Pedro Albéniz (Condesa de Espoz y Mina, 1910: 199, 204, 221; Navarro, 2012: 641-644), quienes serán a su vez profesores de canto y piano, respectivamente, así como vocales del Real Conservatorio de Música y Declamación María Cristina (GFM, 1842: 228; 1846: 285; 1847: 320; 1848: 363); institución que en sus primeros años tendría muy en cuenta la estructura y gusto italiano reinante en la sociedad del momento (Montes, 1997; 2011).

Durante la niñez de Isabel II, como expone Celsa Alonso (2004: 216), se avanzaría en la modernización de la vida musical del país. Por una parte, regresarían músicos exiliados de París mostrando las nuevas tendencias musicales y fundamentalmente a partir del real decreto del asociacionismo (1839) se crearían liceos, se abrirían salones de baile, se autorizarían nuevamente los bailes de máscaras y se desarrollaría el comercio editorial de partituras dirigido a una naciente burguesía ansiosa de diversión, con deseo de figurar, de ver y ser vistos, así como de mostrar su poder económico.

En los años sucesivos a la proclamación y jura de Isabel II como reina constitucional, celebrada el 1 de Diciembre de 1843 (Colección de las leyes..., 1843: 353), observamos cómo los gobiernos moderados de Narváez y Bravo Murillo favorecerían las artes líricodramáticas y la implantación social de la música teatral y el baile en perjuicio de la música sinfónica y de cámara (Alonso, 2004: 217). En este sentido, observamos cómo en el año 1849 se mostraría una especial afición hacia el baile y el canto, (Subirá, 1949: 43). Isabel II sería promotora de algunos de estos eventos, celebrándose lujosos conciertos bajo la dirección de Francisco Frontera de Valldemosa en Palacio, audiciones en las que, en algunas ocasiones,

\footnotetext{
${ }^{1}$ Para una mayor simplicidad en la lectura se han utilizado una serie de abreviaturas en el presente estudio, las cuales se desarrollan a continuación: Almanaque musical y de teatros (AMT), Archivo General de Palacio (AGP), Archivo del Real Conservatorio Superior de Música de Madrid (ARCSMM), Correo de los teatros (CDLT), Diario constitucional de Palma (DCDP), Diario oficial de avisos de Madrid (DODADM), El Católico (EC), El Clamor público (ECP), El Eco del comercio (EEDC), El Heraldo (EH), El Historiador palmesano (EHP), El Observador (EO), El Popular (EP), Guía de Forasteros en Madrid (GFM), La Época (LEP), La España (LES), La Esperanza (LE), La Ilustración (LI), Sa (Sección administrativa).

${ }^{2}$ Nótese entre la bibliografía existente desde el ámbito historiográfico estudios de época y textos de las primeras décadas del siglo XX de autores como Cambronero (1908; 1975), Luz (1937), Llorca [1956] así como investigaciones recientes de Comellas (1999), Vilches (2007) o Burdiel (1998, 2010); pudiéndose destacar entre los estudios centrados en el ámbito musical de corte los realizados por Sopeña Las reinas de España y la música (1984: 103112) así como las investigaciones realizadas por Alonso (1997; 2004).

${ }^{3}$ Aunque por real orden de 15 de julio de 1830 se creó el Real Conservatorio de Música y Declamación María Cristina, hasta el 2 de abril de 1831 no tendría lugar su apertura. Almanaque musical y de teatros, 1868, p. 76.
} 
la propia reina intervenía cantando e interpretando el arpa o el piano (Sopeña, 1984: 107109; Alonso, 2004: 220) ${ }^{4}$.

En este contexto musical, quiso Isabel II tener un teatro en el Palacio Real, como expone Cambronero (1975: 135-138), donde se representarían comedias y óperas en español e italiano, además de realizarse bailes de salón $(E C P, 1926: 3 ; E H, 2593: 3 ; E O, 835: 3 ; E P$, $1358: 4)^{5}$. No se trataría de hacer un escenario provisional como el que sirvió para representar comedias en el cuarto de Fernando VII en la última época de su reinado sino de construir un verdadero teatro en palacio, como se expuso en El Clamor Público (ECP, 1388: 3).

Debemos reseñar cómo con esta iniciativa, los espectáculos líricos de palacio, que habían guardado un largo silencio como consecuencia de la orden dictada por Carlos III en 1777 al prohibirse todo género de representaciones lírico- italianas en los Reales Sitios (Peña y Goñi, 1881: 444; Alonso, 2004: 220), retornan con el mayor esplendor de la mano de la reina Isabel II.

El proceso de construcción de este nuevo emplazamiento de recreo causaría más de un problema por la posible perdida artística que pudiera ocasionarse en el inmueble. En este sentido, el arquitecto mayor del Real Palacio, Narciso Pascual y Colomer, expondría sobre la posible localización del teatro lo que sigue:

"Así pues en mi concepto el punto mejor, el que menos gastos causaría, el que permite hacer la obra en el menor tiempo, el que menos perjudica a la solidez y estabilidad del edificio es el sitio que ocupa el archivo de la casa, para cuya traslación calculo unos veinte mil reales de gasto siempre que pudiera disponerse de la habitación que hoy ocupan los augustos hermanos de S.M. el Rey" (AGP, Sa 668; Subirá, 1950: 169)

La idea sería crear un teatro sin decoraciones de bastidores, iluminado con gas $(E C P, 1473$ : $4)^{6}$ y que contara con tres vestidores para señoras, otros tres para caballeros y uno grande para los que hicieran de comparsas ${ }^{7}$; obra para la cual se mandó que se remitiesen las molduras y adornos de talla dorada de la administración de San Ildefonso (AGP, Sa 668).

\footnotetext{
${ }^{4}$ Téngase en cuenta la existencia de partituras compuestas por Pedro Albéniz y Francisco Frontera de Valldemosa con solos específicos creados para Isabel II, la reina madre y la infanta Luisa Fernanda que serían interpretadas en Palacio en funciones a las que se convidaba a los jefes de Palacio, maestros, azafatas y camaristas así como algunos de los ministros con el objetivo de mostrar los adelantos en materia musical realizados por las princesas. Véase Navarro Lalanda, Sara (2009). "Entorno político-musical de la infancia de Isabel II y la Infanta Luisa Fernanda de Borbón: Villancicos reales de Pedro Albéniz (1795-1855) y Francisco Frontera de Valldemosa (1807-1891)”. La Natividad: arte, religiosidad y tradiciones populares. Francisco Javier Campos y Fernández de Sevilla (coord.), pp. 650-651._ (2012). "La edición musical en la Biblioteca particular de María Cristina de Borbón: interculturalidad de una reina cosmopolita en el escenario español”. Imprenta y edición musical en España (ss. XVIII-XX). Begoña Lolo y José Carlos Gosálvez (eds.). Madrid: Colección de Estudios 148. Universidad Autónoma de Madrid, pp. 313-319), De igual modo, existen noticias de bailes que se efectuaban para el entretenimiento de sus altezas. Espoz y Mina, Condesa de: Memorias de la Excma. Sra. Condesa de Espoz y Mina. Madrid: [s.n.], 1910 (Imp. de los Hijos de M. G. Hernández), pp. 292, 297, 382.

${ }^{5}$ Pueden leerse noticias en los anuncios anteriores como la que sigue: "Dicen que S.M. la Reina ha dispuesto que durante la estación de invierno haya los jueves y domingos funciones en el teatro de Palacio: los jueves ópera y los domingos baile". El Clamor público, Núm. 1926 (31 de octubre de 1850), p. [3].

${ }^{6}$ Nótese cómo ya en fecha de 13 de abril de 1849 se procedería a realizar los ensayos del alumbrado de gas en el teatro de Palacio. El Clamor Público, Núm. 1473 (15 de Abril de 1849), p. [4]

${ }^{7}$ Estúdiense los planos del teatro en: Martín, Fernando A. (1997). "Breve historia del Teatro del Real Palacio". En: Reales Sitios. Revista del Patrimonio Nacional, Año XXXIV, no 132 (2º trimestre 1997), pp. 27- 31.
} 
Según las descripciones de Muñoz y Cambronero, el escenario se colocaría en la parte más próxima al Alcázar, situándose una hermosa y elegante tribuna frente al proscenio, donde la familia real presenciaría las funciones y, asimismo, se habilitaría como salón de espera el antedespacho del Rey (Muñoz, 1923: 121; Cambronero, 1975: 135).

Para no aumentar la deformidad de la fachada se haría de quita y pon el tambor, que desde el balcón del antedespacho de Su Majestad daría entrada a la escalera del teatro, sólo usándose este sistema cuando hubiera necesidad.

Si algo nuevo merece de reseñar en el nuevo teatro es el estar dotado de ciertos adelantos técnicos en relación a los demás teatros del momento, como se mostraba en los diarios de la época:

"Para que todo sea completo allí, hay una máquina ejecutada por un modesto, pero habilísimo artesano vascongado, la cual es enteramente diferente de la de los demás teatros de la corte, y cuyo mecanismo, desconocido hasta ahora entre nosotros, es un verdadero adelanto. Los bastidores, bambalinas, telones, rompimientos y decoraciones cerradas, se mueven por medio de una combinación de tambores, con una rapidez y precisión asombrosas. El movimiento de los escotillones es también nuevo y de una celeridad admirable. El telar, en fin, así como toda la obra del foso es sólido, sencillo, esbelto, por decirlo así, y revela ese buen gusto que solo es peculiar de los artífices consumados. Hemos procurado indagar el nombre de este artesano, que mas bien debiéramos llamar artista de genio; se llama Lorenzo Cocha, es natural y vecino de Vitoria, y bajo su dirección se han ejecutado todas las obras del escenario". (LES, 309:4; $E C P, 1475: 4)$

En definitiva, el Teatro de Palacio sería concebido como un templo del arte $(L E P, 24: 4)^{8}$, sería un lugar de encuentro a la manera familiar (Subirá, 1849:73) ${ }^{9}$ en el cual convidados, servidumbre y funcionarios distinguidos, en número no superior a 250 personas, compartirían una serie de funciones dramáticas y líricas desarrolladas en un escenario coronado por las grandes glorias de nuestra literatura, entre los que destacaría, Felipe IV, quien, no olvidemos, era, a su vez, el fundador del regio teatro del Buen Retiro (LES, 309:4, 320:4; ECP, 1475: 4):

"Solo sí añadiremos á cuanto se ha dicho, por habernos parecido circunstancia dignísima de atención, que en el friso campean ocho retratos de nuestros mejores escritores del siglo de oro, y en medio de ellos el del señor rey don Felipe IV, sin distinción alguna de los demás, patentizándose, con tan ingeniosa idea, que nuestra joven reina hace gala

\footnotetext{
${ }^{8}$ Nótese cómo las decoraciones serían pintadas por los artistas españoles Llop y Tomé (El Historiador palmesano (EHP), Núm. 17 (7 de mayo de 1849), p. [4]), valiéndose además del maestro francés Philastre, y posiblemente, del maestro italiano Lucini para realizar los decorados de las óperas. Arias del Cossío, A. M. (2001- 2002). "La escenografía operística en el Madrid del siglo XIX”. La ópera en España e Hispanoamérica: actas del Congreso Internacional "La Ópera en España e Hispanoamérica, una Creación Propia", Madrid, 29.XI/3.XII de 1999. Madrid: ICCMU, [2001- 2002], p. 287.

${ }^{9}$ Entre los concurrentes asiduos a los conciertos y representaciones operísticas del teatro del Palacio Real, Subirá destaca a la Reina madre y al suegro morganático, el duque de Riansares, junto a lo más lucido de la corte.
} 
de los títulos literarios de uno de sus preciados ascendientes; que pone las glorias del ingenio al nivel del esplendor del trono" (LES, 309:4; ECP, 1475: 4) $)^{10}$.

\section{Miembros integrantes de las representaciones del teatro de palacio}

El Teatro de Palacio concluiría sus obras a principios de abril ${ }^{11}$, tal y como muestra la prensa de la época $(E C P, 1473: 4 ; E O, 378: 4 ; L E S, 305: 4)^{12}$, inaugurándose en el día de la festividad del cumpleaños de María Cristina de Borbón, la reina madre $(E C P, 1469$ : 4, 1470: 4; EO, 384: 4; LE, 1397: 4; LEP, 8: 4).

La apertura del Teatro de Palacio sería en los días próximos a la inauguración un tema de preocupación para la alta sociedad, no hablándose en estos círculos sino de la puesta en funcionamiento de aquel templo y de quiénes serían los agraciados al convite:

"[...] Mas por desgracia el recinto no es bastante anchuroso para contener la numerosa concurrencia que asiste a las regias fiestas generalmente, y aquí de los temores, de los recelos, de las dudas de cada uno de no verse favorecido con el convite para la primera función dramática.

A los bailes - a los bailes pequeños se entiende- eran invitadas de seiscientas a setecientas personas, así, no habiendo cabida en la sala del nuevo coliseo más que para doscientas cincuenta, una tercera parte casi, debían ser muchas las no favorecidas [...]" (LI, 9:7; $E O, 391: 4)$

Entre la concurrencia figurarían las hijas de María Cristina, la duquesa de Gor, la marquesa de Valverde, la duquesa de Frías, la princesa Carini, la marquesa de Villanueva de las Torres, la condesa de Campo Alange, la de Cimera... "la nata y flor de lo que Madrid ostentaba en hermosura y en elegancia, en alcurnia y en talento, en riqueza positiva y en riqueza intelectual", como expone Cambronero (1975: 136) y la prensa de la época ( $E C P, 1485: 4)$.

Los intérpretes eran, igualmente, un gran misterio, siendo motivo de elucubraciones por parte de los articulistas, quienes propondrían posibles fórmulas de contratación en periódicos como El Clamor público:

“[...] Parece que se abrirá con una comedia de don Ramón Navarrete. Pero ¿quién la hará? ¿Los actores del Teatro Español? ¿Y el estudio y ensayos de esta comedia, no les quitarán tiempo para las otras? Creemos que en el Teatro de Palacio debieran darse las primeras representaciones de las obras nuevas de más importancia, y las segundas ser las primeras para el público en el Teatro Español. Así se practicaba en París, y lo que el Rey daba por este trabajo a los cómicos les formaba un sobresueldo que se consideraba como justo premio de los artistas" (ECP, 1470: 4)

\footnotetext{
${ }^{10}$ Véase más información sobre la decoración y retratos del teatro en La Esperanza, Año V Núm. 1371 (16 de marzo de 1849), p. [3]; El Clamor público, Núm. 1449 (17 de Marzo de 1849), p. [4]; El Clamor público, Núm. 1458 (28 de marzo de 1849), p. [4].

${ }^{11}$ Téngase en cuenta que con posterioridad se realizarían nuevas obras en palacio que alcanzarían, igualmente, al nuevo teatro. La España, Núm. 408 (11 de agosto de 1849), p. [4].

${ }^{12}$ Nótese que la obra del Teatro de Palacio sería suspendida por orden de la reina en semana santa, desde el jueves hasta el sábado santo tras los oficios. El Clamor Público, Núm. 1467 (8 de abril de 1849), p. [4].
} 
Otros periódicos como El Observador harían comentarios más cercanos a la realidad, indicando que se creía "que algunos individuos de los que tomaban parte en las óperas del Teatro de Palacio, serían nombrados músicos de cámara señalándoseles una pensión" $(E O, 511: 4)$. Como diría Cambronero, "las aristocráticas fiestas de este teatro podían haber sido la realización del ideal de un cortesano de Luis XIV" (Cambronero, 1975: 138), comparación que ya en época se emitía en los periódicos:

“[...] La feliz, la generosa idea de llamar al real teatro de Palacio a los actores que más dignos se muestren del aprecio público, no puede menos de dar excelentes frutos. Acaso andando el tiempo, podrán esos actores escogidos adquirir consideración de actores de cámara, a estilo de los comediens ordinaires du Roi que creó en el reino vecino el gran Luis XIV. Acaso también podrá introducirse la costumbre de estrenarse en el real Palacio las obras originales de nuestros ingenios, como con las mejores producciones francesas acontecía en Versalles cuando allí recibió sus mayores estímulos la práctica de las artes escénicas, cuando allí llegó a ser la envidia de todas las naciones cultas. Todo esto y mucho más pueden prometerse nuestros ingenios y nuestros actores, de la joven y bella heredera de Luis XIV y de Felipe IV" (EP, 878: 1; LES, 305: 4)

El mismo día de la inauguración del Teatro de Palacio el periódico El Observador anunciaría que la orquesta se compondría para esta primera representación de 50 profesores, siendo dirigida por Valldemosa, maestro de la reina y director de los conciertos del real palacio. Asimismo, se indicaría que en la comedia del señor Navarrete, Caprichos de la fortuna, tomarían parte los actores del Teatro español: las señoras Diez y Chafino y los señores Romeas y García Luna, padre e hijo (EO, 391: 4, 392: 4).

En este sentido, el anuncio anterior, nos da ya algunas pistas de los intérpretes, pero, deberemos esperar hasta las crónicas de esta primera función para tener conocimiento de la información completa tanto del programa, intérpretes como del público asistente ${ }^{13}$ :

“[...] Brillante cual ninguna estuvo anoche la concurrencia, ya que escasa por desgracia en atención a no contener el teatro más que unos 250 asientos. Distinguíanse alrededor de SS.MM. y de los augustos hermanos del rey el cuerpo diplomático, el general Narváez, casi todos los ministros de la corona, los jefes de palacio y varias notabilidades de nuestra más histórica aristocracia. Dio principio la función a las nueve y media con una sinfonía. Siguió un himno compuesto al intento por el maestro Hernando, y cantado por los alumnos del Conservatorio; luego una comedia en tres actos y en verso, titulada, si no fallan nuestros informes, Caprichos de la fortuna, obra del señor Navarrete, desempeñada por los hermanos Romea, los Sres. García Luna y Sobrado, y las señoras Diez, Llorente y Palma. Se acabó con el conocido sainete titulado: Un diablillo con faldas, desempeñado por los señores Guzmán y Romea (don Florencio) y por la señora Palma [...]" (LES, 320: 4)

A modo de esquema, pueden distinguirse tres grupos diferenciados de intérpretes en las obras que se ejecutarían en el Teatro de Palacio: los miembros de la Real Cámara y Real

\footnotetext{
${ }^{13}$ Véase, en comparación con la crónica que se muestra a continuación la expuesta en El Clamor Público, Núm. 1485 (29 de abril de 1849), p. [4].
} 
Capilla de Palacio, alumnos del Real Conservatorio de Música y Declamación María Cristina y actores de los principales teatros de la villa y corte.

Como antecedente recordaremos que la Real Cámara de Palacio no era una institución de nueva creación. Basta retroceder en el tiempo unas décadas para observar su presencia en el comienzo del reinado de Fernando VII, quien promulgaría una serie de reglamentos que concluirían en la supresión de la misma (Labrador, 2003: 233-266).

Analizando los artículos generales del reglamento de la Real Cámara de 1824 observamos cómo la plantilla de músicos de esta institución había sido eliminada, citándose en su primer artículo la reunificación de la misma con los músicos de la Real Capilla:

"Los músicos que compongan la orquesta de Cámara deberán serlo de la Real Capilla, y no se denominarán de Cámara, los cuales percibirán además del sueldo que gocen por la Capilla la gratificación anual de seis mil reales; esto se entiende con los que entren en adelante, pues los actuales percibirán ambos sueldos como hasta aquí" (AGP, Sa 469; AGP, Sa 945/1)

Por tanto, los puestos como cargos profesionales seguirían existiendo, pero ya no con el calificativo de músicos de cámara y con la diferenciación en el importe de los sueldos, ya que desde este momento se percibiría como suplemento y no como un nuevo empleo, abaratando, de esta forma, los costes que suponían al erario real; normativa que continuaría vigente durante la regencia de María Cristina de Borbón, como se desprende del reglamento de 1838 (AGP, Sa 945/1; AGP, Sa 468/1).

En contraposición con la política de reducción de gastos que había llevado María Cristina de Borbón, su hija, Isabel II, decidiría restablecer la Real Cámara siendo notificado por la misma al Duque de Hijar de la siguiente forma:

"Hijar. Vengo en restablecer la real cámara en la parte vocal para lo cual tengo a bien crear las plazas siguientes. Una de tiple, una de contralto, una de tenor de medio carácter, una de tenor serio, una de barítono y una de bajo. Los cuales tendrán la obligación de asistir a mi Real Cámara y cantar en los conciertos y en las óperas cuando yo tenga a bien mandar. Sus sueldos serán los que señalare en el decreto de su nombramiento. Lo tendrás entendido y lo comunicarás a quien corresponda. Dado en Palacio a 19 de Diciembre de 1849" (AGP, Sa 668) ${ }^{14}$

De entre estos músicos, que serían, los primeros cantantes del teatro, podemos destacar a Manuela Oreiro Lema de Vega y a Joaquín Reguer, procedentes, ambos, de la formación obtenida en el Real Conservatorio de Música y Declamación María Cristina ${ }^{15}$.

\footnotetext{
${ }^{14}$ Obsérvese el texto reproducido por Subirá en el cual sólo es citado el tenor serio, no siendo nombrado el tenor "de medio carácter" expuesto en el presente estudio. Subirá, J. (1950). El Teatro del Real Palacio (18491851)..., Op. cit., p. 179.

${ }^{15}$ Manuela Oreiro Lema de Vega formaría parte del grupo de los primeros alumnos internos gratuitos del Real Conservatorio de Música y Declamación María Cristina. (Saldoni, B. (1868- 1881). Diccionario biográfico-bibliográfico de efemérides de músicos españoles. Madrid (calle del Pez, núm. 6, principal): Antonio Pérez Dubrull, vol. 2, 1868-1881, p. 376- 381; ARCSMM, AHA, Leg. 1/12. [En 6 de Octubre de 1830]). De igual modo, puede citarse cómo Joaquín Reguer estudiaría canto en el Real Conservatorio de Música y Declamación María Cristina con Piermarini, director de la institución (Saldoni, B. (1868-1881). Diccionario biográfico-bibliográfico de efemérides de músicos españoles..., Op. cit., p. 392).
} 
Entre las obligaciones de estos músicos estaba el asistir a los actos propios de Palacio tales como funciones del teatro o besamanos (AGP, Sa 668) ${ }^{16}$ así como a otra serie de eventos externos de beneficencia como la función celebrada a favor del profesor de clarinete Tomás Fasseno en el gran salón del Liceo (ECP, 1970: 3; LEP, 551: 3), o las realizadas en beneficio de la Inclusa (Navarro, 2012: 1008-1023; ECP, 1747: 3; LEP, 312: 4).

Por otra parte, siguiendo lo expuesto por Soriano Fuertes (1855: 392), los músicos de la Real Capilla de palacio constituirían la orquesta en las representaciones del teatro con refuerzo de algunos profesores distinguidos de la corte.

En segundo lugar, puede ser destacada la participación de los alumnos del conservatorio, quienes, por lo general, constituirían los coros, como expone Cambronero (1975: 136), interpretando himnos corales como el del acto de apertura del Teatro de Palacio, del cual se muestra a continuación la parte de bajo:

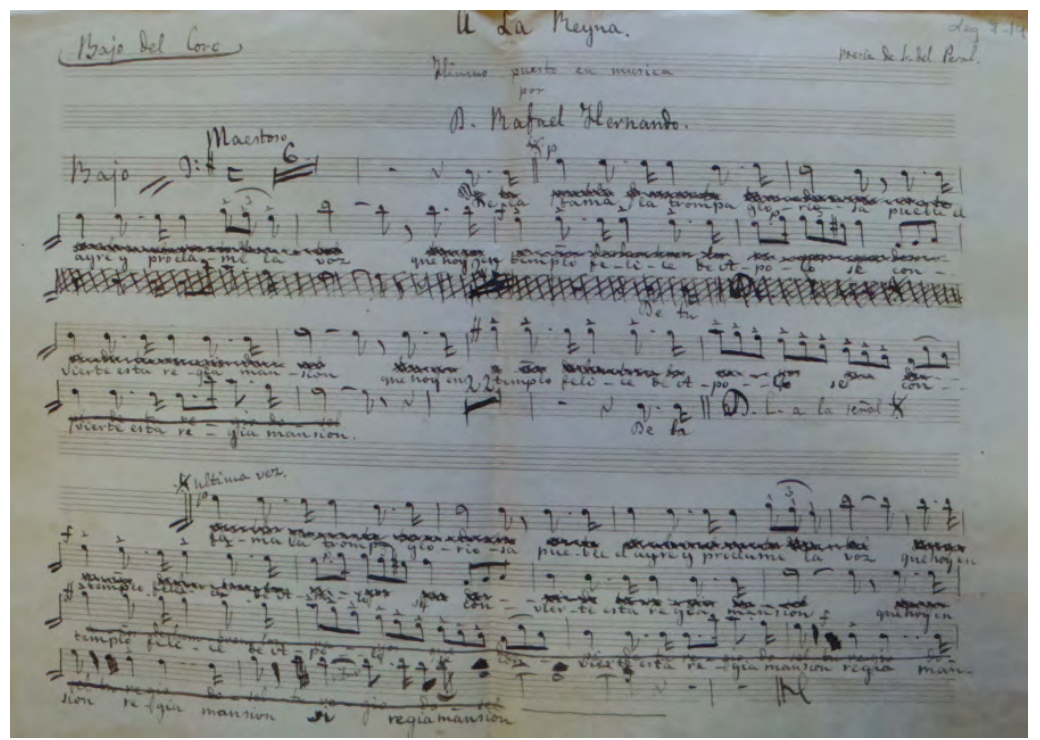

Imagen 1. A la Reina. Parte de Bajo del himno puesto en música por Rafael Hernando. Poesía del Sr. Del Peral (ARCSMM, Leg. 7/14)

\footnotetext{
${ }^{16}$ Véase, asimismo, como se hace eco la prensa de algunos de estos nombramientos y de sus funciones: El Heraldo, Núm. 2264 (6 de octubre de 1849), p. [4]; El Popular, Año IV Núm. 1030 (8 de octubre de 1849), p. [4]; La Época, Primer Año Núm. 241 (22 de Diciembre de 1849), p. [4]; El Heraldo, Núm. 2328 (22 de diciembre de 1849), p. [4]; El Clamor público, Núm.1685 (23 de Diciembre de 1849), p. [4]; El Popular, Año IV Núm. 1096 (24 de diciembre de 1849), p. [4].
} 
El himno citado con anterioridad sería interpretado por los siguientes alumnos del establecimiento:

Tabla 1: Relación de alumnos del Real Conservatorio de Música y Declamación María Cristina que interpretaron el himno de inauguración del Teatro de Palacio (ARCSMM, Leg. 7/14)

\begin{tabular}{|c|c|c|c|c|}
\hline TIPLES & CONTRALTOS & TENORES & BAJOS & $\begin{array}{l}\text { SOLOS } \\
\text { ESTROFAS }\end{array}$ \\
\hline Teresa Isturiz & [Rosario] Díaz & [Mariano]Sessé & [José] García & \multirow{4}{*}{$\begin{array}{l}\text { [Amalia] Anglés } \\
\text { Antonia Isturiz } \\
\text { [Joaquina] } \\
\text { Gamiz } \\
\text { Corona }\end{array}$} \\
\hline $\begin{array}{l}\text { [Manuela] } \\
\text { Ramírez }\end{array}$ & [Emilia] Dávila & $\begin{array}{l}\text { [Salvador] } \\
\text { Velázquez }\end{array}$ & $\begin{array}{l}\text { [Martín] } \\
\text { Urruzunu }\end{array}$ & \\
\hline $\begin{array}{l}\text { [Eladia] Apari- } \\
\text { cio }\end{array}$ & [Isabel] García & [Lázaro] Robles & [José] Scriú & \\
\hline [Josefa] Santafé & [Dolores] Alegre & \multirow[t]{4}{*}{ Goldi } & $\begin{array}{l}\text { [Manuel] } \\
\text { Cáceres }\end{array}$ & \\
\hline \multirow[t]{3}{*}{$\begin{array}{l}\text { [Manuela] } \\
\text { López }\end{array}$} & \multirow[t]{3}{*}{ [Mercedes]Urtiaga } & & $\begin{array}{l}\text { [Juan] } \\
\text { Castellanos }\end{array}$ & \multirow{3}{*}{$\begin{array}{l}\text { [Pablo] Hijosa } \\
\text { [Manuel]Hernán- } \\
\text { dez }\end{array}$} \\
\hline & & & [Anacleto] Díaz & \\
\hline & & & Begoña & \\
\hline
\end{tabular}

Las representaciones dramáticas serían un segundo escenario en el que participarían alumnos del conservatorio, siendo muestra de ello tanto la lista de coros de la ópera La Conquista de Granada, remitida por Emilio Arrieta a Wenceslao Muñoz, secretario de la institución (ARCSMM, Leg. 7/68) ${ }^{17}$, como la notificación de los alumnos que tomarían parte en la ópera La Straniera (ARCSMM, Leg. 7/51; AGP, Sa 669).

En último lugar, debe tenerse en cuenta la participación de intérpretes de los teatros públicos; hecho que conllevaría el tener que ponerse de acuerdo las distintas instituciones para no coincidir en sus actuaciones, tal y como sucedería en marzo de 1850 anunciándose en el periódico La España lo siguiente:

"Se ha suspendido el ensayo general de El astrólogo fingido que esta noche debía verificarse en el teatro de palacio; y también se ha aplazado su representación hasta que concluyan las de La madre de san Fernando en el teatro Español, por tener papeles en este drama algunos actores que también los tienen en El astrólogo" $\left(\right.$ LES, 590:4) ${ }^{18}$

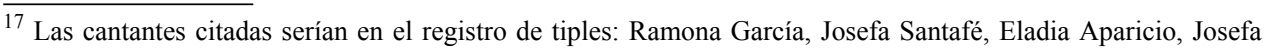
Angulo, María Chasse, Antonia Millera, Antonia Velarde, Carolina López; como contraltos: Dolores Alegre, Matilde Torrentera, Juana López, Manuela López, Adela Creart [sic], Francisco Lamas, Manuela Ramírez, Luisa Breu.

${ }^{18}$ Obsérvese otra casuística de coincidencia de funciones en La Época, Segundo Año Núm. 293 (17 de febrero de 1850), p. [4].
} 


\section{Representaciones del Teatro de Palacio}

El elenco de representaciones que se pretendían poner en funcionamiento en el Teatro de Palacio era una incógnita para todos. La prensa anunciaba noticias erróneas entre las que se llegaba a especular tanto sobre cuáles serían las funciones a representar ${ }^{19}$ representar como sobre la participación de la propia reina en las mismas en noticias como las que siguen:

"Dícese también que S. M. tomará parte en el desempeño de la mencionada ópera, pero no nos atrevemos dar crédito á esta noticia" (ECP, 1441: 4)

"Ya que un periódico ha revelado que la primera ópera que se pondrá en escena en el teatro de Palacio será la Ana Bolena, de Donizeti, lo cual no habíamos querido anunciar nosotros por creer que S.M. lo miraba todavía como un secreto, añadiremos hoy que á la Ana Bolena seguirá la no menos bella partitura de Bellini, titulada: Montequi ed $i$ Capuletti, y que en ambas desempeñará la Reina, según se nos ha dicho, el papel principal, cuyo estudio parece tiene ya muy adelantado la augusta señora” (EP, 849: 3)

"Parece que estas últimas noches las destina S.M. la Reina al ensayo de la función que debe verificarse en el nuevo teatro de palacio la próxima Pascua" (ECP, 1454: 4; LE, 1377: 4; DCDP, 6: 3)

Por otra parte, el número de representaciones que tuvieron lugar en el que sería el último esce-nario de ópera en los reales sitios sería también una temática escurridiza, incluso en la actua-lidad. Según Carmena y Millán, serían en número veinticuatro las representaciones ejecutadas, alternando La Straniera, La Conquista de Granada e Ildegonda, siempre con el mismo reparto (Carmena y Millán, 2002: 18-20; Alonso, 2004: 220).

Los documentos de pagos a cantantes nos indican que al menos se efectuó otra ópera en dicho teatro, Luisa Miller, además de las representaciones de comedias, citándose el número en veintiséis, tal y como se presenta a continuación (AGP, Sa 669; Subirá, 1950: 246-248):

\begin{tabular}{|lc|}
\hline Ildegonda & 10 funciones \\
Estraniera [sic] & 8 funciones \\
Isabel & 3 funciones \\
Luisa Miller & 2 funciones \\
Astrologo & 1 \\
Sino vieran [sic] & 1 \\
Inauguración & 1 \\
--------------------------- \\
Total... & 26 \\
\hline
\end{tabular}

\footnotetext{
${ }^{19}$ Véase otra muestra de las noticias erróneas que circularon con anterioridad a la apertura del Teatro de Palacio "Una de las primeras óperas que se cantarán en el teatro de palacio será, según parece, la del joven D. Martín Sanchez Allú, titulada El feudo de las cien doncellas, de que tiene conocimiento S.M. la reina”. La Época, Segundo Año Núm 367 (14 de mayo 1850), p. [4].
} 
Asimismo, entre los legajos de Palacio encontramos dos notas no datadas que hacen alusión a esta temática: la primera de ellas expone las obras junto a las fechas en que fueron interpretadas, siendo su número tan sólo de $17^{20}$, mientras que en la segunda se hace referencia a los gastos de refrescos consumidos en dichas funciones, según la cual se habrían efectuado 26 representaciones ${ }^{21}$.

En el presente estudio se ha procedido a realizar a través de la prensa de la época un aná lisis teniendo en cuenta los anuncios y crónicas de las representaciones, tomando en conside ración tanto las funciones como los ensayos ya que, en ocasiones, como muestra la noticia del periódico La Época, éstos últimos eran abiertos al público:

"Anoche se verificó en el teatro de Palacio el ensayo general de La Straniera, ejecutándose con decoraciones y trajes, y estando el teatro iluminado, sin que faltase nada de lo que constituye una verdadera representación. Puede decirse que anoche se puso en escena la ópera, pues habiéndose repartido billetes para asistir a esta función, la sala se hallaba enteramente ocupada por una brillantísima concurrencia, estando S.M. la reina en uno de los palcos" [...] $(L E P, 270: 4)$

A modo de esquema, hemos realizado la siguiente tabla en la que se exponen las obras y número de representaciones y ensayos realizados de cada función a través del estudio de la prensa de época:

Tabla 2: Relación de funciones, ensayos y representaciones del Teatro de Palacio

\begin{tabular}{|l|l|l|}
\hline OBRAS/FUNCIÓN & $\begin{array}{l}\text { AUTORES DE LAS } \\
\text { OBRAS }\end{array}$ & $\begin{array}{l}\text { ENSAYOS } \\
\text { Y } \\
\text { REPRESENTACIONES }\end{array}$ \\
\hline $\begin{array}{l}\text {-Caprichos de la fortuna } \\
\text { (comedia en tres actos) } \\
\text {-Un diablillo con faldas (sainete) }\end{array}$ & Ramón de Navarrete & 2 Representaciones (R) \\
\hline Ildegonda & $\begin{array}{l}\text { Poesía de Temístocles Solera } \\
\text { Música de Emilio Arrieta }\end{array}$ & $\begin{array}{l}\text { ca. } 17 \\
(6 \text { Ensayos }(\mathrm{E})+c a .11 \mathrm{R}\end{array}$ \\
\hline $\begin{array}{l}\text { La Straniera (ópera en 2 actos) } \\
\text { Letra de Romani } \\
\text { Música de Vincenzo Bellini }\end{array}$ & $\begin{array}{l}\text { ca. } 13 \\
(6 \mathrm{E}+\text { ca. } 7 \mathrm{R})\end{array}$ \\
\hline $\begin{array}{l}\text { en } 5 \text { actos) } \\
\text {-El Pan pan y el vino vino }\end{array}$ & $\begin{array}{l}\text {-Pedro Calderón de la Barca } \\
\text { o refundición de Dionisio } \\
\text { Solís } \\
\text {-Anónimo }\end{array}$ & $\begin{array}{l}3 \\
(2 \mathrm{E}+1 \mathrm{R})\end{array}$ \\
\hline
\end{tabular}

${ }^{20}$ Consúltense las fechas de las representaciones en el apéndice documental, donde el documento es citado como AGP, Sa 669 (2).

${ }^{21}$ Consúltense las fechas de las representaciones en el apéndice documental, donde el documento es citado como AGP, Sa 669 (1). Nótese que Subirá se refiere, igualmente, a un legajo con gastos de repostería aunque las fechas indicadas no son idénticas a las mostradas con anterioridad. Subirá. J. (1950). El teatro del Real Palacio..., Op. cit., pp. 247- 248 . 


\begin{tabular}{|c|c|c|}
\hline $\begin{array}{l}\text { La Conquista de Granata (ópera } \\
\text { seria en } 3 \text { actos) }\end{array}$ & $\begin{array}{l}\text { Letra de Temístodes Solera } \\
\text { Música de Emilio Arrieta }\end{array}$ & $\begin{array}{l}c a .7 \\
(1 \mathrm{E}+6 \mathrm{R})\end{array}$ \\
\hline Luisa Miller (ópera en 3 actos) & $\begin{array}{l}\text { Letra de Salvator Cam- } \\
\text { marano } \\
\text { Música de Giuseppe Verdi }\end{array}$ & ca. $4 \mathrm{R}$ \\
\hline $\begin{array}{l}\text {-Si no vieran las mujeres } \\
\text { (comedia) } \\
\text { - ¿Un ente singular! (comedia en } \\
\text { un acto) }\end{array}$ & $\begin{array}{l}\text {-Lope de Vega o refundición } \\
\text { de Manuel Bretón de los } \\
\text { Herreros } \\
\text {-Don Ramón de Navarrete }\end{array}$ & 2 \\
\hline $\begin{array}{l}\text { Función de monos y perros sapi- } \\
\text { entes }\end{array}$ & - & $1 \mathrm{R}$ \\
\hline
\end{tabular}

De las óperas representadas, serían estrenos en España, Luisa Miller, Ildegonda y La Conquista de Granada, siendo, por el contrario, obra ya representada en el escenario español La Straniera; pieza de Bellini de gran trascendencia en el ámbito español si atendemos al número de representaciones que se efectuaron de la misma ${ }^{22}$.

No debemos olvidar que nos encontramos en un momento de lucha por establecer la ópera española, con iniciativas como la de Dionisio Scarlatti de Aldama al crear en 1845 la Academia Real de Música y Declamación o, asimismo, la sociedad desarrollada en 1847 por músicos como Eslava, Velaz de Medrano, Arrieta, Barbieri, Basili, Martin Salas, Gaztambide, Peña y Goñi... denominada La España Musical (Peña y Goñi, 1881:306- 307; Alonso, 20012002: 25-26). Con lo anterior, quiero destacar cómo en el teatro de Palacio estuvo presente tanto la ópera de compositores italianos como las de un español, Arrieta.

Aunque tendríamos un compositor español en plantilla de la Real Cámara así como temática de signo nacional en óperas como La conquista de Granada (Cortizo, 2006a:616621), la ópera autóctona no llegaría a desarrollarse en el teatro de palacio, quizás por falta de un verdadero apoyo real.

Las funciones, tanto de comedias como operísticas, fueron, en todo momento, consideradas excelsas en las crónicas de los periódicos de la época, expresándose incluso cómo "al presenciar semejantes funciones se viene a la memoria la época en que se daban tan brillantes fiestas en la corte del Buen Retiro" (LES, 557: 4).

Estas funciones cumplían con los tres requisitos que periódicos como La España indicaba necesarias para el completo éxito de toda producción lírica: mérito real y verdadero en la música que se cantaba, ejecución esmerada y lujo y propiedad en los trajes y decoraciones; características éstas que cumplía el Teatro de Palacio "gracias a la protección que dispensa doña Isabell II a las artes, al gusto exquisito que preside a todas sus determinaciones, y la generosidad con que S.M. abre las arcas de su tesoro, a fin de que las funciones que se dan en su regio alcázar sean dignas del trono español" (LES, 557: 4).

Estudiando las crónicas de la época, observamos cómo algunas comedias nuevas fueron tan bien acogidas que serían repuestas inmediatamente en los teatros madrileños, como nos

\footnotetext{
22 Téngase en cuenta cómo La Straniera había sido representada con anterioridad en el Teatro del Príncipe el 3 de diciembre de 1830, 19 de enero de 1832, 30 de abril de 1832, 18 de septiembre de 1834 y en el Teatro de la Cruz el 13 de mayo de 1837, en abril de 1839 y el 7 de febrero de 1840 (Carmena y Millán, L. (2002). Crónica de la ópera italiana en Madrid. Madrid: Ediciones ICCMU, pp. 73, 75, 76, 80, 85, 87 y 89).
} 
muestra el periódico El Heraldo que aconteció con la comedia Caprichos de la fortuna de Navarrete:

"Según dice la Época, el Sr. Navarrete ha recibido por conducto del comisario regio del teatro Español una lisonjera invitación del señor conde de San Luis para que se represente inmediatamente en aquel coliseo la comedia con que se inauguró el del real palacio, titulada Caprichos de la fortuna, a lo cual ha accedido el Sr. Navarrete. En su consecuencia, dicha comedia se pondrá en escena a mediados de la semana próxima" $(E H, 2162: 4)$

Si nos adentramos en las funciones operísticas de autores italianos, observamos alabanzas tanto a las interpretaciones de La Straniera (CDLT, 7:2 $)^{23}$ como a la de Luisa Miller (CDLT, 22: 1$)^{24}$. En este sentido, un ejemplo de la repercusión de estas obras en la sociedad del momento se muestra en el Diario oficial de avisos de Madrid, anunciando la venta de la última ópera citada para canto y piano, piano solo y a cuatro manos tanto en el gran almacén de música y pianos de Salazar (DODADM, 186: 4, 187: 3), como en el almacén de música de Lodre (LES, 989: 4, 991: 4).

En consideración con las obras de Arrieta, parece que los reyes quedaron tan complacidos de la ópera Ildegonda ${ }^{25}$-obra compuesta en 1844 durante su etapa de aprendizaje en el Conservatorio de Música de Milán, establecimiento en que sería estrenada-, que su obertura fue escuchada en diversos programas: en conciertos de Palacio (EP, 1423: 2; LES, 854: 3), en el Teatro Nuevo de Variedades (DODADM, 1094: 4) y en el Teatro del Príncipe (LES, 1059: 4); siéndole solicitado por encargo al compositor de cámara el escribir otra obra nueva, La Conquista de Granada ${ }^{26}$, a la que seguiría la ópera inconclusa, Pergolese, que estaba pensada se ejecutara, de igual modo, en dicho teatrino; obras, todas ellas, que seguirían los cánones italianos tanto en el idioma de los textos escritos por el poeta Temístocle Solera como al seguir el paradigma italiano en lo musical (Cortizo, 1998a: 479,481,492).

En este sentido, la segunda ópera del compositor, La Conquista de Granada ${ }^{27}$, representada en palacio en el día del veinte cumpleaños de la reina, en la que participaría la prima donna Rosmini de Solera (CDLT, 10:4), acudiendo como público invitado el príncipe Jorge de Prusia $(E P, 1060: 1)$, recibiría crónicas tan positivas que, incluso, compararían algunos de sus movimientos con las mejores obras de compositores de renombre en el panorama español:

\footnotetext{
${ }^{23}$ Estúdiense, asimismo, crónicas de la ópera como las que siguen: El Heraldo, Núm. 2355 (24 de enero de 1850), p. [3]; La España, Año $3^{\circ}$ Núm. 557 (1 de febrero de 1850), p. [4]; El Heraldo, Núm. 2377 (19 de febrero de 1850), p. [4]; El Clamor Público, Núm. 1976 (22 de diciembre de 1850), p. [2].

${ }_{24}$ Véanse otras crónicas de Luisa Miller como la expuesta en El Heraldo, Núm. 2747 (2 de mayo de 1851), p. [3].

${ }^{25}$ Como ejemplo de las crónicas a los ensayos y conciertos véase: El Clamor Público, Núm. 1611 (3 de octubre de 1849), p. [4]; El Clamor Público, Núm. 1649 (16 de noviembre de 1849), p. [4]; El Heraldo, Núm. 2298 (16 de noviembre de 1849), p. [3].

${ }^{26}$ De entre las referencias de la prensa sobre la creación de esta nueva ópera véase La España, Núm. 464 (14 de octubre de 1849), p. [4].

${ }^{27}$ Entre los anuncios de esta ópera encontramos la publicada en Correo de los teatros, Año I Núm. 8 (12 de enero de 1851), p. [4]. Véase la litografía de época de dicha representación en La Ilustración, Núm. 46 (16 de noviembre de 1850), p. [5] y Subirá, J. (1950). El Teatro del Real Palacio (1849-1851)..., Op. cit., p. 176.
} 
“[...] El final del acto segundo es una gran pieza concertante, escrita con mucha maestría y con cierto gusto clásico, que nos hizo recordar las mejores obras del célebre Mercadante" (LEP, 495: 4) ${ }^{28}$

Es conocido cómo una vez realizadas en el Teatro de Palacio estas óperas, el compositor de la real cámara obtendría permiso para pasar a Italia (Milán, Génova y Turín) a fin de representar dichas obras, tal y como fue ampliamente difundido en la prensa española (CDLT, 29: 3, 38: 3; EH, 2780: 3, 2797: 3; EO, 949: 3, 1051: 3; EP, 1476: 3, 1539: 4; LEP, 625: 3), siendo, igualmente, ejecutada poco tiempo después, según Peña y Goñi, en Lisboa (Peña y Goñi, 1881:445) y en el Teatro Real de Madrid ${ }^{29}$. En este sentido, el reconocimiento sería tal que por orden real serían grabadas dichas partituras (LES, 841: 4).

Como último punto a tratar en lo que atañe a las representaciones, no hay que olvidar que nos encontramos estudiando una institución política, lo que conllevaría seguir las pautas o normativas de estado, tales como la suspensión de representaciones, por ejemplo, ante fallecimiento de algún miembro de la realeza o cargo político ${ }^{30}$.

Uno de los acontecimientos más tensos que se viviría en este teatro sería el denominado "golpe de Estado", que tendría lugar el 19 de Octubre de 1849 como consecuencia de haber recibido una carta días antes Isabel II procedente de su esposo cuyo resumen venía a mostrar que el ministerio estaba comprometiendo la suerte del trono. Ya Vilches nos indica cómo los invitados a la velada de teatro fueron testigos de la escena (Vilches, 2007: 140-141), la cual exponemos a continuación:

“[...] La función, pues, comenzó cerca de las doce de la noche. La concurrencia, más escasa que las noches anteriores, estaba ya bajo la impresión del acontecimiento que acababa de verificarse; y como quiera que no lo supiese todavía, presentía la fatal gravedad de alguna circunstancia imprevista. S.M. el rey se mostraba tranquilo y complacido; pero la fisonomía de S.M. la reina revelaba el combate interior de contrarios afectos. Según personas que asistieron al espectáculo, S.M. se hallaba verdaderamente conmovida. No se veía allí a ninguno de los señores ministros ni a sus familias. La

\footnotetext{
${ }^{28}$ Ténganse, igualmente, en cuenta entre las crónicas de esta ópera la realizada en La España, Año $3^{\circ}$ Núm. 774 (15 de octubre de 1850), p. [4] así como su posterior reposición en 1855 en el Teatro Real (Cortizo, Ma . E. (1998). "Emilio Arrieta, operista frustrado: Ildegonda y La Conquista de Granada". Revista de Musicología, vol. XX, n. 1, p. 503).

${ }^{29}$ Encontramos, por el contrario, una apreciación no tan favorable en relación a la segunda representación de Ildegonda en España, en este caso en una función realizada en el Teatro Real. Aunque se aguardaba con gran expectación tras su puesta en escena en el Teatrino de Palacio y en Italia, el resultado ante el público no sería el esperado, según las palabras de Carmena y Millán "Todos los artistas interpretaron la obra con acierto. El éxito fue mediano" (Carmena y Millán, L., 2002). Crónica de la ópera italiana en Madrid..., Op. cit., p. 206). Hay que hacer notar que no sería el mismo elenco de cantantes el que representaría tal ópera en ambos escenarios: Los cantantes de la representación en el Teatro de Palacio fueron Joaquín Reguer, Manuela Oreiro de Lema, Antonio Castells de Pons, Pablo Hijosa, Francisco Calvet, Teresa Istúriz (Cortizo, Ma . E. (1998). "Emilio Arrieta, operista frustrado...", Op. cit., p. 481) mientras que en el del Teatro Real fueron la Gazzaniga, Malvezzi, Echevarría y Baillou (Carmena y Millán, L., 2002). Crónica de la ópera italiana en Madrid ..., Op. cit., p. 206).

${ }^{30}$ Ejemplo de ello será la suspensión de la función del 17 de octubre de 1850 de La Conquista de Granada por el fallecimiento de la reina de los belgas, motivo por el cual hubo dos semanas de luto en la corte española. La España, Año $3^{\circ}$ Núm. 778 (19 de octubre de 1850), p. [4]
} 
función se apresuró algún tanto, y concluyó bajo tristes auspicios [...]”( $L E P, 179: 1)$ 31

\section{Gastos del Teatro de Palacio: ¿derroche o suntuosidad de la realeza?}

En relación a los gastos causados tanto por la construcción del teatro del Real Palacio como por las funciones que en éste se ejecutaron, el contador general remite adjunta una nota el 12 de Julio de 1851 en la que se expone grosso modo las siguientes cuentas ${ }^{32}$ :

\begin{tabular}{|c|c|}
\hline -Gastos de construcción y habilitación del Teatro de Palacio & .215 .436 \\
\hline \multicolumn{2}{|l|}{-Gastos ocurridos para la representación de la comedia } \\
\hline Caprichos de la fortuna & 14.169_14 \\
\hline -Ildegonda (opera) & 312.023 \\
\hline -La extranjera [La Straniera](opera) & 301.014 \\
\hline -El astrólogo fingido (comedia) & 90.293 \\
\hline -La Conquista de Granada (opera) & 349.061_30 \\
\hline -Si no vieran las mujeres (comedia) & 146.989_16 \\
\hline -Luis[a] Miller (ópera) & 322.829_30 \\
\hline -La Sonambula (ópera) & 64.1 \\
\hline -Sueldos de los empleados del Teatro & 297.673 \\
\hline -Derechos de aduana de trajes traídos de París & 125.994 \\
\hline
\end{tabular}

Fuente: AGP, Sa 668; Subirá, 1950: 255-258.

Como se desprende de lo expuesto, podemos decir que no tendían a llevar una política moderada de gasto sino todo lo contrario ${ }^{33}$. La iluminación con lámparas de araña al igual que gran parte de los vestuarios de las óperas venían de París (AGP, Sa 668) ${ }^{34}$; asimismo se contrataban decoradores y todo tipo de material que fuera necesario para la escena y para

\footnotetext{
${ }^{31}$ Léase el acontecimiento también en: El Eco del comercio, Tercera época Año XVI, Núm. 7 (21 de octubre de 1849), p. [2]; El Católico, Núm. 3269 (20-21 de octubre de 1849), p. 142- 143; El Heraldo, Núm. 2277 (21 de octubre de 1849), p. [2].

${ }^{32}$ Nótese que en el resumen mostrado, que es la conclusión de un desglose de gastos, que puede ser observado también en Subirá, las cuentas no estaban del todo claras, pues si se realiza la suma de la totalidad de las partidas que figuran en el resumen de gastos no coincide con el total presentado en el propio resumen. Asimismo, adviértase que existe al menos otro expediente con cuentas relativas a los gastos del Teatro de Palacio en el que sólo contamos con el resumen pudiendo afirmarse que al ser de cuantía inferior seguramente sería de un estudio de gasto precedente. Subirá, José. (1950) El Teatro del Real Palacio (1849-1851)..., Op. cit., p. 250; AGP, Sección administrativa 669. ${ }^{33}$ En la prensa se menciona este asunto como sigue: "Según hemos oído, el presupuesto del teatro que se está construyendo en el piso bajo de palacio asciende a cuarenta mil duros, no contándose en esta cantidad más que las obras de fábrica; pues las decoraciones, lucerna para el alumbrado y demás objetos que son indispensables formarán otra cuenta”. El Clamor Público, Núm. 1400 (21 de enero de 1849), p. [4].

${ }^{34}$ Existen diversas peticiones entre las que podemos citar el encargo por parte del arquitecto mayor de Palacio a Pedro Gil de los aparatos necesarios para proceder a la iluminación con gas del teatro así como los trabajos de vestuario y decorados realizados por Philastre en esta misma ciudad. Nótese la minuciosidad con que fueron realizados los diseños de vestuario en noticias como "El señor Méndez ha hecho un Álbum del teatro de palacio con
} 
lo musical: alquileres de pianos con la afinación que esto ocasionaba (AGP, Sa 669), reconstrucción de tambores cilíndricos a la francesa como los del teatro Real de Oriente (AGP, Sa 669), así como decoraciones nuevas para las distintas representaciones (EO 496: 3, 596: 4; EH, 2348: 4; LES, 442: 4, 543: 4; LE, 1626: 4; EP, 1013: 3; ECP, 1407: 4, 1606: 4, 1700 : 4).

En lo referido al pago de la plantilla de músicos, las cantidades a pagar serían también considerables. En primer lugar, citamos los sueldos de los miembros de la plantilla de la Real Cámara, los cuales serían de muy diferente cuantía, siendo los puestos mejor remunerados los de tenor, tiple y maestro director, mientras que, por el contrario, el de menor remuneración sería el de avisador (AGP, Sa 669; Subirá, 1950:260).

Nótese cómo en ocasiones, estos salarios iban acompañados de algunos presentes que la reina ofrecía a sus músicos como signo de complacencia hacia su labor:

"Hemos tenido el gusto de ver un magnífico alfiler de oro, brillantes y esmeraldas que S.M. la Reina ha regalado al maestro compositor don Emilio Arrieta, autor de la Ildegonda: es de un trabajo exquisito y muy propio para la persona a quien ha sido regalado" $(L E, 1552: 3)^{35}$

Asimismo, ofrecemos como ejemplo desglosado, aunque de forma esquemática, el gasto ocasionado al pagar a los profesores de música de la Real Capilla y profesionales externos por representaciones de las óperas La Straniera, Ildegonda, La Conquista de Granada y Luisa Miller:

los figurines ideados, dibujados y pintados por él. Los de La Conquista de Granada sorprendieron en París a donde se mandaron para la confección de los trajes por la maestría y buen gusto con que estaban compuestos y ejecutados" mostrada en La España, Año IV Núm. 841 (2 de Enero de 1851), p. [4] y de contenido similar en La Ilustración, Año 50 Núm. 46 (16 de noviembre de 1850), p. [5]. Véase, asimismo, los envíos de dicho vestuario procedentes de París en El Clamor Público, Núm. 1702 (18 de enero de 1850), p. [4]; El Heraldo, Núm. 2350 (18 de enero de 1850), p. [4]; La Ilustración, Año 50 Núm. 46 (16 de noviembre de 1850), p. [5].

${ }^{35}$ Véanse, de igual forma, sobre estos regalos regios: El Popular, Año IV Núm. 1036 (15 de octubre de 1849), p. [4]; El Clamor Público, Núm. 1622 (16 de octubre de 1849), p. [3]; La España, Núm. 476 (28 de octubre de 1849), p. [4]; El Observador, Núm. 530 (29 de octubre de 1849), p. [3]; El Popular, Año IV Núm. 1050 (31 de octubre de 1849), p. [4]. 
Tabla 6: Sueldos global por plantillas instrumentales (AGP, Sa 669)

\begin{tabular}{|c|c|c|c|c|c|}
\hline & \multicolumn{2}{|c|}{$\begin{array}{l}\text { LA } \\
\text { STRANIERA }\end{array}$} & ILDEGONDA & $\begin{array}{l}\text { LA CONQUISTA } \\
\text { DE GRANADA }\end{array}$ & $\begin{array}{l}\text { LUISA } \\
\text { MILLER }\end{array}$ \\
\hline $\begin{array}{l}\text { FECHAS DE } \\
\text { REPRESENTACION }\end{array}$ & $\begin{array}{l}\text { Febr. } \\
1850\end{array}$ & $\begin{array}{l}16 \text { Dic. } \\
1850\end{array}$ & $\begin{array}{l}23,27 \text { Feb. } \\
2 \text { Marzo } \\
1850\end{array}$ & $\begin{array}{l}10,13,30 \\
\text { Octubre } \\
1850\end{array}$ & $\begin{array}{l}27 \text { Abr } \\
4 \text { Mayo } \\
1851\end{array}$ \\
\hline ORQUESTA & 55050 & \multirow[t]{2}{*}{11090} & 19650 & \multirow[t]{2}{*}{57240} & \multirow[t]{2}{*}{27690} \\
\hline BANDA & 6160 & & 2880 & & \\
\hline CORO HOMBRES & 25200 & 4140 & 5760 & 26640 & \multirow[t]{2}{*}{33620} \\
\hline CORO MUJERES & - & 3910 & 6120 & 18870 & \\
\hline APUNTADOR & \multirow[t]{4}{*}{5480} & \multirow[t]{2}{*}{1010} & \multirow[t]{3}{*}{1680} & 2290 & \multirow[t]{4}{*}{3486} \\
\hline AVISADOR & & & & \multirow[t]{3}{*}{2790} & \\
\hline MOZO & & - & & & \\
\hline COMPARSAS & & 522 & - & & \\
\hline COPIAS & - & - & - & 7681 & - \\
\hline \multirow[t]{2}{*}{ TOTAL } & \multirow[t]{2}{*}{91890} & \multirow[t]{2}{*}{ [20672] } & \multirow[t]{2}{*}{36090} & 115511 & \multirow[t]{2}{*}[64796]{} \\
\hline & & & & $\begin{array}{l}\text { [con reposi- } \\
\text { ciones:]14.0511 }\end{array}$ & \\
\hline
\end{tabular}

Para comprender la diferencia en las cantidades pagadas a los músicos deben ser tenidos en cuenta tanto el número de ensayos como de conciertos efectuados de cada ópera.

El pago de los músicos, ya fueran pertenecientes a la Real Capilla como profesores convidados a dichas funciones, era realizado, normalmente, a través de Francisco Frontera de Valldemosa, quien ejercía la función de director de conciertos. En relación a las remuneraciones, queremos mostrar tanto que existían distintas categorías entre los instrumentistas como que los ensayos eran pagados con una menor remuneración que las funciones (AGP, Sa 669; Subirá, 1950: 208-209, 222-225, 231-232). Por otra parte, debe tenerse en cuenta que el sueldo ofrecido a los músicos variaría en función de la tipología de repertorio, siendo remunerados los músicos en las representaciones de las comedias a un importe inferior que en las funciones operísticas.

Entre las partidas de gasto encontramos también aquellas referidas a la dotación del material musical. En este sentido, puede observarse la vinculación con Francisco Conde así como con el editor Bernabé Carrafa a quienes suceden varios pagos desde 1849 por la compra de diversas piezas de música, incluyendo música sacra, y siendo, en ocasiones, indicado que estas partituras eran para consumo de la reina.

En este sentido, no debemos olvidar que para nutrir este teatro sería imprescindible la copia de música, siendo Daniel Sebastián Gabalda quien, junto a Facundo Bonet, encargado de la impresión de los ejemplares, y Miguel Ginesta, encuadernador del repertorio, se encargarían de dicho cometido. 


\section{El final de un sueño ajeno a las posibilidades reales: el cese de la Real Cámara y Teatro del Palacio Real}

Tras dos años de funcionamiento del Teatro de Palacio y de la cámara real, y continuando el mismo proceso seguido para su formación, es decir, a través de una notificación de la reina al duque de Hijar, fue comunicado el cese de dichas instituciones:

"Hijar. Atendiendo a las razones que me ha expuesto mi Intendente General de la Real Casa y Patrimonio, vengo en suprimir mi cámara de música y canto y el teatro de Palacio, clasificando a todos sus individuos según su tiempo de servicio. Lo tendrás entendido y lo comunicaras a quien corresponda" (AGP, Sa 669; Subirá, 1950:244)

De este modo, se redactó un escrito con fecha de 30 de junio de 1851 en el cual se les notificaba lo antedicho a los interesados, los cuales mostramos a continuación:

- Francisco Frontera de Valldemosa, Maestro Director

- Emilio Arrieta, Maestro Compositor

- Manuela Oreiro de Vega, Tiple

- Sofia Vela, Contralto

- Lázaro Puig, Tenor

- Joaquín Reguer, Bajo

- Adolfo Gironella, Barítono del Teatro de Palacio

- Francisco Barbieri, 1er. Apuntador del Teatro de Palacio

- Justo Moré, Maestro de coros del Teatro de Palacio

- Bernardino Moreno, Avisador del Teatro de Palacio

- Daniel Sebastián Gabaldás, copiante de música del Teatro de Palacio

- Temistocles Solera, Poeta italiano del Teatro de Palacio (AGP, Sa 668)

Asimismo, los medios de comunicación se harían eco de la noticia exponiendo reseñas del tipo: "En la intendencia de la Real Casa, según hemos oído, se van a hacer algunas economías, siendo una de ellas el suprimir enteramente todos los gastos que origina el teatro de palacio, a los que se deben en parte el notable atraso que sufren los intereses del patrimonio" (EO, 1046: 3)

Tras el cese de actividad del Teatro se daría la real orden de desocupar la caballeriza de todos los efectos pertenecientes al Teatro de Palacio y del Real de Oriente. En lo que atañe a la plantilla de la Real Cámara, se dispuso que Francisco Frontera de Valldemosa y Joaquín Reguer quedasen en el mismo ser y estado que tenían en la Real Casa antes del restablecimiento de la Cámara en la parte vocal y que la clasificación de los individuos que componían la Real Cámara de música y canto y el Teatro de Palacio se hiciese en el concepto de jubilación (AGP, Sa 668).

Si comenzamos nuestra andadura observando cuál fue el origen de las instalaciones del teatrino, sólo queda mostrar el nuevo destino de este archivo rehabilitado para teatro en la exposición del arquitecto mayor de Palacio:

"S.M. la reina N[uestra] S[eñora] se ha dignado resolver que el local en que hoy está situado el Teatro de este Real Palacio, se destine a gabinete de física, demoliendo la parte que sobresale en la terraza, regularizando el aspecto público, y ejecutando las 
obras que V[uestra] S[eñoría] contemple necesarias p[ar]a que el local aparezca de la manera que sea conveniente al objeto a que se le destina" (AGP, Sa 668)

Como indica Cortizo, haciendo referencia al libro Escenografía española de Muñoz, las decoraciones del Teatro pasarían al Real Conservatorio de Música y Declamación María Cristina pereciendo dicho material en el incendio habido en 1867 (Cortizo,1998a:480). Sobre este particular, podemos afirmar que las decoraciones y objetos varios, entre los que se encuentran aparatos de gas para el alumbrado pertenecientes al teatro de este Real Palacio, serían por Real Orden de 9 de abril de 1853 enviados al Real Conservatorio de Música y Declamación María Cristina. Este material sería remitido junto con un inventario, que se encuentra en la actualidad en el archivo del Real Conservatorio Superior de Música de Madrid, el cual está clasificado teniendo en cuenta la procedencia de los objetos. De entre las comedias encontramos material de Si no vieran las mujeres y El astrólogo; mientras que de las óperas existen efectos de El Regente, La Conquista de Granada, Luisa Miller, La Sonnambula, La Straniera y de una obra denominada sin especificar, probablemente Ildegonda (ARCSMM, Leg. 9-9; 9-52).

De igual forma, la reina aprobaría la adquisición para el conservatorio de los trajes que fueron del teatro del Real Palacio por la cantidad de ciento sesenta mil reales de vellón, según la escritura otorgada por Ramón Balloni y Gregorio Morales Pantoja como apoderado de Humanite Philastre a favor del conservatorio ante Juan García de Lamadrid, secretario honorario de la reina y notario del reino en 30 de marzo de 1854 (ARCSMM, Leg. 9-52).

Según consta en la prensa de la época, como se indica a continuación, las decoraciones y trajes serían utilizados por los alumnos en las representaciones del teatro del conservatorio:

"La función dada el sábado en el conservatorio de María Cristina estuvo brillantísima. [...]. Las bellas decoraciones y los riquísimos trajes que se estrenaron para el teatro de palacio en La conquista de Granada, regalados por S.M. al conservatorio, dieron gran realce á la representación de Alzira" (LEP, 1525:3).

El sueño de la reina sería un delirio filarmónico regio, como expone Alonso (2004: 221), imposible de mantener económicamente, aunque daría su fruto, pues la ópera italiana se habría convertido en el símbolo del poder económico y distinción social indispensable para la alta burguesía del momento. Aún así, el apoyo de Isabel II y del gobierno moderado seguiría vigente durante la construcción del nuevo emplazamiento de recreo, el Teatro Real, encontrándonos noticias en que la citan como posible mecenas $(L E P, 751: 3)^{36}$.

\section{Conclusiones}

El teatrino de Palacio, en todas sus facetas, fue en su corto espacio de vida un escenario cortesano en el que destacar y realzar el esplendor de la corona:

- La infraestructura del teatrino no tendría igual en la corte madrileña. No hay más que recordar las nuevas técnicas en la maquinaria del teatro, iluminación a gas, acabados en mármol, retratos de nuestros antepasados literatos y reales, escenarios y vestuarios traídos

\footnotetext{
${ }^{36}$ Véase, igualmente, El Clamor Público, Núm. 2150 (13 de julio de 1851), p. [3].
} 
de París... elementos todos ellos que mostrarían una riqueza y esplendor propio de las grandes cortes europeas.

- El teatro de palacio sería un lugar de encuentro de la alta sociedad de la época, donde sus miembros, como círculo de influencia, participarían en la construcción de los acontecimientos económico- sociales de la corte así como de la política.

- Las representaciones operísticas seguirían el paradigma italiano belcantista y no la búsqueda de una ópera nacional, incluso en las nuevas obras creadas y dirigidas por el músico español Arrieta; mientras que, en las funciones teatrales se daría un total apoyo a la creación autóctona, tanto de autores contemporáneos, como Ramón de Navarrete, como a las de autores del teatro clásico.

- El Conservatorio de Música y Declamación María Cristina sería el productor de buena parte de los músicos presentes en las representaciones del Teatro de Palacio. Algunos de estos discípulos serían artistas de primera línea ya consagrados, que pasarían a formar parte de la Real Cámara de Palacio. Por otra parte, a los alumnos, aún estudiantes de la citada institución, se les brindaría la oportunidad de participar en el Teatro de Palacio como intérpretes corales; artistas a los que hay que sumar los propios de la Real Capilla y profesores externos que formarían parte de la orquesta y banda.

- Un público selecto de 250 personas-asientos de que constaba el teatro-sería el elegido para vislumbrar el esplendor de la corona y ser, a su vez, el referente cortesano español. El número reducido de lunetas llevaría a realizar distintas representaciones de cada función e, incluso, conllevaría que ciertos ensayos fueran, igualmente, públicos a fin de dar cabida a un mayor número de invitados.

Tras dos años de representaciones, los gastos excesivos, a todas luces, que ocasionaban estos eventos para tan reducido número de personas, junto a la aparición del Teatro Real en escena conllevaría el cierre en 1851 del Teatro de Palacio, sueño dorado de Isabel II. 


\section{Referencias}

Alonso, C. (1997). La canción lírica española en el siglo XIX. Madrid: ICCMU, [1997]. Texto basado en el trabajo de tesis Canción y Sociedad en la España decimonónica: 1800-1874, dirigida por Emilio Casares Rodicio inserta en la Base de Datos de Tesis en red Teseo.

— (2001-2002). "La ópera romántica española hasta la apertura del Teatro Real (1800- 1850)". La ópera en España e Hispanoamérica: actas del Congreso Internacional "La Ópera en España e Hispanoamérica, una Creación Propia", Madrid, 29.XI/3.XII de 1999. Madrid: ICCMU, pp. 7- 62.

- (2004). "La música isabelina: el anverso lírico de un reinado azoroso". En: Isabel II. Los espejos de la reina. Juan Sisinio Pérez Garzón (ed.). Madrid: Marcial Pons Historia, pp. 213-230.

Arias del Cossío, A. M. (2001-2002). "La escenografía operística en el Madrid del siglo XIX”. La ópera en España e Hispanoamérica: actas del Congreso Internacional "La Ópera en España e Hispanoamérica, una Creación Propia", Madrid, 29.XI/3.XII de 1999. Madrid: ICCMU, pp. 283-292.

Burdiel Bueno, I. (1998). “Isabel II: Un perfil inacabado". En: La política en el reinado de Isabel II. Madrid: Asociación de Historia Contemporánea- Marcial Pons, 1998.

- (2010). Isabel II: una biografía (1830-1904). Madrid: Taurus.

Cambronero, C. (1908). Isabel II intima: apuntes histórico anecdóticos de su vida y de su época. Barcelona: Montaner y Simon.

- (1975). Isabel II. Madrid: Círculo de Amigos de La Historia.

Carmena y Millán, L. (2002). Crónica de la ópera italiana en Madrid. Madrid: Ediciones ICCMU.

Comellas, J. L. (1999). Isabel II. Una reina y un reinado. Barcelona: Ariel, 1999.

Cortizo, Ma . E. (1998a). "Emilio Arrieta, operista frustado: Ildegonda y La Conquista de Granada". Revista de Musicología, vol. XX, n. 1, pp. 479-503

- (1998b) Emilio Arrieta: de la ópera a la zarzuela. Madrid: Instituto Complutense de Ciencias Musicales, 1998.

- (2006a) "Alhambrismo operístico en "La conquista di Granata" (1850) de Emilio Arrieta: mito oriental e histórico en la España romántica”. Príncipe de Viana, Año n ${ }^{\circ} 67, \mathrm{~N}^{\circ} 238$ (Ejemplar dedicado a: Conmemoración del VIII Centenario de la Chantría de la Catedral de Pamplona como dignidad eclesiástica (1206-2006) / coord. por María Gembero Ustárroz), pp. 609-632.

- (2006b). "Emilio Arrieta vuelve al Real: El coliseo lírico madrileño apuesta por 'La conquista di Granata"'. Opera actual, No. 92, pp. 30-31.

Espoz y Mina, Condesa de. (1910). Memorias de la Excma. Sra. Condesa de Espoz y Mina. Madrid: [s.n.] (Imp. de los Hijos de M. G. Hernández).

Labrador, G. (2003). "Música, Poder e Institución: La Real Capilla de Carlos IV (1788-1808)". Revista de Musicología, XXVI, nº 1, pp. 233-266.

Llorca, C. (1956). Isabel II y su tiempo. Alcoy: Marfil (Valencia: Tip. Moderna).

Luz, P. de. (1937). Isabel II. Reina de España (1830-1904). Barcelona: Juventud.

Martín, Fernando A. (1997). "Breve historia del Teatro del Real Palacio". Reales Sitios. Revista del Patrimonio Nacional, Año XXXIV, nº 132, pp. 27-31.

Marco, J. M. (2008). “Isabel II y la ópera. Del Teatro de Palacio al Palacio Real”. La Ilustración liberal: revista española y americana, $\mathrm{N}^{\mathrm{o}} .36$, pp. 77-100.

Montes, B. C. (1997). "La influencia de Italia y Francia en el Real Conservatorio de Madrid". La investigación musical en España: estado de la cuestión y aportaciones: actas del IV Congreso de la Sociedad de Musicología Española, Revista de Musicología XX, 1, pp. 467-478.

- (2011). "La institucionalización de la enseñanza musical en España: La recepción de la ópera italiana en la fundación del Real Conservatorio de Madrid”. Comunicación realizada en el XVI coloquio nacional de historia de la educación. Arte y oficio de enseñar. Dos siglos de perspectiva histórica. 11 al 13 de julio de 2011.

Muñoz Morillejo, J. (1923). Escenografía española. Madrid: Imp. Blass 
Navarro Lalanda, S. (2009). "Entorno político-musical de la infancia de Isabel II y la Infanta Luisa Fernanda de Borbón: Villancicos reales de Pedro Albéniz (1795-1855) y Francisco Frontera de Valldemosa (1807-1891)". La Natividad: arte, religiosidad y tradiciones populares. Francisco Javier Campos y Fernández de Sevilla (coord.), pp. 637-652.

- (2012a). "El Real Conservatorio de Música y Declamación María Cristina: Conciertos externos realizados por su alumnado". Actas de I Encontro Ibero America de jovens musicólogos (Cd). Tagus-Atla/Ticus associação cultural, pp. 1008-1023.

— (2012b). "La edición musical en la Biblioteca particular de María Cristina de Borbón: interculturalidad de una reina cosmopolita en el escenario español”. Imprenta y edición musical en España (ss. XVIII- XX). Begoña Lolo y José Carlos Gosálvez (eds.). Madrid: Colección de Estudios 148. Universidad Autónoma de Madrid, pp. 309-324.

Peña y Goñi, A. (1881). La ópera española y la música dramática en España en el siglo XIX. Madrid (carrera de San Jerónimo, 34): Zozaya; Madrid (calle de laAlmudena, 2): Imp. y esterotipia de El liberal.

- (2004). La ópera española y la música dramática en España en el siglo XIX. Madrid: ICCMU.

Rueda Hernanz, G. (2001). Isabel II. Madrid: Arlanza.

Saldoni, B. (1868-1881). Diccionario biográfico-bibliográfico de efemérides de músicos españoles. Madrid (calle del Pez, núm. 6, principal): Antonio Pérez Dubrull, 4 vols.

Sopeña Ibáñez, F. (1984). Las reinas de España y la música. [Bilbao]: Banco de Bilbao, pp. 103-112. Soriano Fuertes, M. (1855-1859). Historia de la música española desde la venida de los fenicios hasta el año de 1850. Madrid; Barcelona; Martín y Salazar: Narciso Ramírez, 1855-1859

- (2007). Historia de la música española desde la venida de los fenicios hasta el año de 1850. Madrid: ICCMU.

Subirá, J. (1949). Historia y Anecdotario del Teatro Real. Madrid: Editorial Plus·ultra.

- (1950). El Teatro del Real Palacio (1849-1851) con un bosquejo preliminar sobre la música palatina desde Felipe V hasta Isabel II. Madrid: Consejo Superior de Investigaciones Científicas, Instituto Español de Musicología).

Vilches, J. (2007). Isabel II. Imágenes de una reina. Madrid: Síntesis.

\section{Fuentes de hemeroteca}

Almanaque musical y de teatros (AMT), 1868, p. 76

Correo de los Teatros (CDLT), Año I Núm. 7 (5 de Enero de 1851), p. [2]; Año I Núm. 8 (12 de Enero de 1851), p. [4]; Año I Núm. 10 (26 de Enero de 1851), p. [4]; Año I

Núm. 22 (4 de Mayo de 1851), p. [1]; Año I Núm. 29 (15 de Junio de 1851), p. [3]; Año I Núm. 38 (17 de Agosto de 1851), p. [3].

Diario Constitucional de Palma (DCDP), Núm. 6 (4 de Abril de 1849), p. [3].

Diario Oficial de Avisos de Madrid (DODADM), Núm. 186 (5 de Mayo de 1851), p. [4]; Núm. 187 (6 de Mayo de 1851), p. [3]; Núm. 1094 (30 de Octubre de 1850), p. [4].

El Católico (EC), Núm. 3269 (20- 21 de Octubre de 1849), p. 142-143.

El Clamor Público (ECP), Núm. 1388 (7 de Enero de 1849), p. [3]; Núm. 1400 (21 de Enero de 1849), p. [4]; Núm. 1407 (27 de Enero de 1849), p. [4]; Núm. 1441 (8 de Marzo de 1849), p. [4]; Núm. 1449 (17 de Marzo de 1849), p. [4]; Núm. 1454 (23 de Marzo de 1849), p. [4]; Núm. 1458 (28 de Marzo de 1849), p. [4]; Núm. 1467 (8 de Abril de 1849), p. [4]; Núm. 1469 (11 de Abril de 1849), p. [4]; Núm. 1470 (12 de Abril de 1849), p. [4]; Núm. 1473 (15 de Abril de 1849), p. [4]; Núm. 1475 (18 de abril de 1849), p. [4]; Núm. 1485 (29 de Abril de 1849), p. [4]; Núm. 1606 (18 de Septiembre de 1849), p. [4]; Núm. 1611 (3 de Octubre de 1849), p. [4]; Núm. 1622 (16 de Octubre de 1849), p. [3]; Núm. 1649 (16 de Noviembre de 1849), p. [4]; Núm. 1685 (23 de Diciembre de 1849), p. [4]; Núm. 1700 (16 de Enero de 1850), p. [4]; Núm. 1702 (18 de Enero de 1850), p. [4]; Núm. 1747 (9 de Marzo de 1850), p. [3]; Núm. 1926 (31 de Octubre de 1850), p. [3]; Núm. 1970 (15 de Diciembre de 1850), p. [3]; Núm. 
1976 (22 de Diciembre de 1850), p. [2]; Núm. 2150 (13 de Julio de 1851), p. [3]; Núm. 2723 (3 de Junio de 1853), p. [3].

El Eco del Comercio (EEDC), Tercera época Año XVI, Núm. 7 (21 de Octubre de 1849), p. [2].

El Heraldo (EH), Núm. 2162 (9 de Junio de 1849), p. [4]; Núm. 2264 (6 de Octubre de 1849), p. [4]; Núm. 2277 (21 de Octubre de 1849), p. [2]; Núm. 2298 (16 de Noviembre de 1849), p. [3]; Núm. 2328 (22 de Diciembre de 1849), p. [4]; Núm. 2348 (16 de Enero de 1850), p. [4]; Núm. 2350 (18 de Enero de 1850), p. [4]; Núm. 2355 (24 de Enero de 1850), p. [3]; Núm. 2377 (19 de Febrero de 1850), p. [4]; Núm. 2593 (1 de Noviembre de 1850), p. [3]; Núm. 2609 (20 de Noviembre de 1850), p. [3]; Núm. 2747 (2 de Mayo de 1851), p. [3]; Núm. 2780 (3 de Junio de 1851), p. [3]; Núm. 2797 (25 de Junio de 1851), p. [3]. 2El Heraldo (Madrid. 1842).

El Historiador Palmesano (EHP), Núm. 17 (7 de Mayo de 1849), p. [4].

El Observador (EO), Núm. 351 (10 de Marzo de 1849), p. [3]; Núm. 378 (11 de Abril de 1849), p. [4]; Núm. 384 (18 de Abril de 1849), p. [4]; Núm. 392 (27 de Abril de 1849), p. [4]; Núm. 496 (18 de Septiembre de 1849), p. [3]; Núm. 511 (6 de Octubre de 1849), p. [4]; Núm. 530 (29 de Octubre de 1849), p. [3]; Núm. 596 (16 de Enero de 1850), p. [4]; Año III Núm. 835 (31 de Octubre de 1850), p. [3]; Año IV Núm. 949 (13 de Marzo de 1851), p. [3]; Año IV Núm. 1046 (12 de Julio de 1851), p. [3]; Año IV Núm. 1051 (18 de Julio de 1851), p. [3]. El Popular (EP), Año IV Núm. 849 (8 de Marzo de 1849), p. [3]; Año IV Núm. 851 (10 de Marzo de 1849), p. [4]; Núm. 878 (12 de Abril de 1849), p. [1]; Año IV Núm. 1013 (18 de Septiembre de 1849), p. [3]; Año IV Núm. 1030 (8 de Octubre de 1849), p. [4]; Año IV Núm. 1050 (31 de Octubre de 1849), p. [4]; Año IV Núm. 1060 (12 de Noviembre de 1849), p. [1]; Año IV Núm. 1096 (24 de Diciembre de 1849), p. [4]; Año V Núm. 1358 (1 de Noviembre de 1850), p. [4]; Año VI Núm. 1423 (17 de Enero de 1851), p. [2]; Año VI Núm.1476 (20 de Marzo de 1851), p. [3]; Año VI Núm. 1539 (4 de Junio de 1851), p. [4].

Guia de Forasteros en Madrid (GFM), 1842, p. 228; 1846, p. 285; 1847, p. 320; 1848, p. 363

La Época (LEP), Año I Núm. 8 (11 de Abril de 1849), p. [4]; Año I Núm. 24 (29 de Abril de 1849), p. [4]; Primer Año Núm. 179 (20 de Octubre de 1849), p. [1]; Primer Año Núm. 241 (22 de Diciembre de 1849), p. [4]; Segundo Año Núm. 271 (24 de Enero de 1850), p. [4]; Segundo Año Núm. 293 (17 de Febrero de 1850), p. [4]; Segundo Año Núm. 312 (9 de Marzo de 1850), p. [4]; Segundo Año Núm 367 (14 de Mayo 1850), p. [4]; Segundo Año Núm. 495 (11 de Octubre de 1850), p. [4]; Segundo Año Núm. 551 (15 de Diciembre de 1850), p. [3]; Tercer Año Núm. 625 (13 de Marzo de 1851), p. [3]; Año tercero Núm. 751 (6 de Agosto de 1851), p. [3]; Núm. 1525 (28 de Febrero de 1854), p. [3].

La España (LES), Núm. 305 (12 de Abril de 1849), p. [4]; Núm. 309 (17 de Abril de 1849), p. [4]; Núm. 320 (29 de Abril de 1849), p. [4]; Núm. 408 (11 de Agosto de 1849), p. [4]; Núm. 442 (19 de Septiembre de 1849), p [4]; Núm. 464 (14 de Octubre de 1849), p. [4]; Núm. 476 (28 de Octubre de 1849), p. [4]; Año $3^{\circ}$ Núm. 543 (16 de Enero de 1850), p. [4]; Año $3^{\circ}$ Núm. 557 (1 de Febrero de 1850), p. [4]; Año $3^{\circ}$ Núm. 590 (12 de Marzo de 1850), p. [4]; Año $3^{\circ}$ Núm. 774 (15 de Octubre de 1850), p. [4]; Año $3^{\circ}$ Núm. 778 (19 de Octubre de 1850), p. [4]; Año IV, Núm. 841 (2 de Enero de 1851), p. [4]; Año IV Núm. 854 (17 de Enero de 1851), p. [3]; Año IV Núm. 989 (25 de Junio de 1851), p. [4]; Año IV Núm. 991 (27 de Junio de 1851), p. [4]; Año IV Núm. 1059 (14 de Septiembre de 1851), p. [4].

La Esperanza (LE), Año V Núm. 1371 (16 de Marzo de 1849), p. [3]; Año V Núm. 1377 (23 de Marzo de 1849), p. [4]; Año V Núm. 1380 (27 de Marzo de 1849), p. [4]; Año V Núm. 1397 (17 de Abril de 1849), p. [4]; Año VI Núm. 1552 (17 de Octubre de 1849), p. [3]; Año VI Núm. 1626 (15 de Enero de 1850), p. [4]; Año VII Núm. 1878 (20 de Noviembre de 1850), p. [3]. La Ilustración (LI), Tomo I Núm. 9 (28 de Abril de 1849), p. [7]; Núm. 39 (27 de Septiembre de 1851), p. [3]; Núm. 46 (16 de Noviembre de 1850), p. [5]

Archivo General de Palacio (AGP), Sección administrativa (Sa) 468/1, 469, 668, 669, 945/1.

Archivo del Real Conservatorio de Música de Madrid (ARCSMM), Leg. 7/14; 7- 51; 7/68; 9-9; 9-52. 
REVISTA INTERNACIONAL DE CIENCIAS HUMANAS

Colección de las leyes, decretos y declaraciones de las Cortes, y de los reales decretos, ordenes, resoluciones y reglamentos generales expedidos por los Respectivos Ministerios. Madrid: Imprenta Nacional, [1843-1846].

Fuentes del Archivo General de Palacio (AGP).

Fuentes del Archivo del Real Conservatorio de Música de Madrid. 
APÉNDICE DOCUMENTAL*

\begin{tabular}{|c|c|c|c|}
\hline \multicolumn{4}{|l|}{ ILDEGONDA } \\
\hline FЕСНА & $\begin{array}{l}\text { EDICIONES } \\
\text { DE ÉPOCA }\end{array}$ & INTÉRPRETES & FUENTES \\
\hline 26 Septiembre 1849 (E) & \multirow{12}{*}{$\begin{array}{l}\text {-Ildegonda } \\
\text { Drama lírico... } \\
\text { que ha de } \\
\text { Representarse } \\
\text { en el Teatro del } \\
\text { Real Palacio el } \\
\text { día } 10 \text { de } \\
\text { Octubre de } 1849 \\
\text { [Poesía de } \\
\text { Temístocles } \\
\text { Solera; Música } \\
\text { del Maestro } \\
\text { Emilio Arrieta]. } \\
\text { Madrid: [S.n.], } \\
1849 \text { (Imprenta } \\
\text { Nacional)** }\end{array}$} & \multirow{12}{*}{$\begin{array}{l}\text { Manuela Oreiro y } \\
\text { Lema de Vega, } \\
\text { Teresa Isturiz, } \\
\text { Antonio Castell de } \\
\text { Pons, Pablo Hijosa, } \\
\text { Joaquín Reguer, } \\
\text { Francisco Calvet y } \\
\text { coros de conser- } \\
\text { vatorio } \\
\text { (Carmena y Millán, } \\
\text { 2002:19) }\end{array}$} & LEP, 156:4 \\
\hline 27 Septiembre 1849 (E) & & & $E C P, 1615: 4$ \\
\hline 30 Septiembre 1849 (E) & & & LES, 453:4 \\
\hline 9 Octubre 1849 (E) & & & $E C P, 1617: 4 ; L E, 1546: 3$ \\
\hline 10 Octubre 1849 & & & $\begin{array}{l}\text { AGP, Sa } 669(1-2) ; \text { Car- } \\
\text { mena y Millán, 2002:19; } \\
E C P, 1592: 4,1618: 3 ; \\
E H, 2269: 4 ; E O, 515: 3, \\
516: 4 ; E P, 1004: 3,1036: 4 ; \\
L E, 1537: 4 ; L E P, 152: 4, \\
169: 4,170: 4,172: 4 ; L E S \text {, } \\
432: 4,461: 3,463: 4 ; L I, \\
33: 1 \text {; Subirá: } 247\end{array}$ \\
\hline 11 Octubre 1849 & & & $\begin{array}{l}\text { AGP, Sa } 669(1-2) ; \\
E P, 1060: 1 ; E H, 2269: 4 ; \\
L E P, 172: 4 ; L E S, 463: 4 ; \\
\text { Subirá: 247; Cambronero, } \\
\text { 1975: } 136\end{array}$ \\
\hline 14 Octubre 1849 & & & $\begin{array}{l}\text { AGP, Sa } 669 \text { (1-2); } E H \text {, } \\
\text { 2271:3; Subirá: } 247\end{array}$ \\
\hline 17 Octubre 1849 & & & Cambronero, 1975:136 \\
\hline 18 Octubre 1849 & & & $\begin{array}{l}\text { AGP, Sa } 669 \text { (1-2); } \\
\text { Subirá: } 247\end{array}$ \\
\hline 22 Octubre 1849 & & & AGP, Sa 669 (1) \\
\hline $\begin{array}{l}11 \text { Noviembre } 1849\left(6^{\mathrm{a}}\right. \\
\text { REP) }\end{array}$ & & & $\begin{array}{l}\text { AGP, Sa } 669 \text { (1); EH, } \\
\text { 2295:4; EP 1060:1; LEP } \\
\text { 203:4; LES, 485:4; Subirá: } \\
247\end{array}$ \\
\hline $\begin{array}{l}14 \text { Noviembre } 1849 \\
\left(7^{\mathrm{a}} \mathrm{REP}\right)\end{array}$ & & & $\begin{array}{l}\text { AGP, Sa } 669(1) ; E C P \\
1649: 4 ; E H, 2298: 3 ; \\
E P, 1063: 2 ; L E S, 492: 4\end{array}$ \\
\hline
\end{tabular}




\begin{tabular}{|c|c|c|c|}
\hline \multicolumn{4}{|c|}{ LA STRANIERA } \\
\hline FECHA & EDICIONES DE ÉPOCA & INTÉRPRETES & FUENTES \\
\hline $\begin{array}{l}\text { 14 Diciembre } \\
1850(\mathrm{E})\end{array}$ & \multirow{11}{*}{$\begin{array}{l}\text {-La Estranjera, melodrama que } \\
\text { ha de representarse en el } \\
\text { Teatro del Real Palacio el día } \\
20 \text { de Enero de } 1850 . \text { Madrid: } \\
\text { por Aguado, impresor de cá- } \\
\text { mara de S.M. y de su Real } \\
\text { Casa, } 1850 .\end{array}$} & \multirow{5}{*}{$\begin{array}{l}\text { Manuela Oreiro y Lema de } \\
\text { Vega, Amalia Anglés, Anto- } \\
\text { nio Castell de Pons, Pablo } \\
\text { Hijosa, José Manzocchi, } \\
\text { Francisco Calvet, Leopoldo } \\
\text { López (Carmena y Millán, } \\
\text { 2002:19) } \\
\text { la señora de Vega y la } \\
\text { señorita Anglés, y los } \\
\text { señores Castell, Hijosa, } \\
\text { Monzochi [sic], Calbet [sic] } \\
\text { y Fernández (EEDC, 45:4; } \\
E C P, 1662: 4 ; L E P, 221: 4)\end{array}$} & $L E P, 550: 3$ \\
\hline $\begin{array}{l}15 \text { Diciembre } \\
1850(\mathrm{E})\end{array}$ & & & $E P, 1397: 4$ \\
\hline $\begin{array}{l}16 \text { Diciembre } \\
1850\end{array}$ & & & $\begin{array}{l}\text { AGP, Sa } 669 \\
(1-2) ; E H, \\
2631: 3 ; \\
\text { Subirá: } 248\end{array}$ \\
\hline $\begin{array}{l}20 \text { Diciembre } \\
1850 \text { (E) }\end{array}$ & & & $C D L T, 5: 4$ \\
\hline $\begin{array}{l}\text { ¿10 Enero de } \\
1850 ?\end{array}$ & & & $\begin{array}{l}E C, 3327: 8 ; \\
E C P, 1688: 4 ; \\
E P, 1103: 3\end{array}$ \\
\hline $\begin{array}{l}20 \text { Enero } \\
1850\end{array}$ & & \multirow[t]{6}{*}{$\begin{array}{l}\text { Lema, Castell, Gironella } \\
(C D L T, 5: 4 ; E C P, 1976: 2)\end{array}$} & $\begin{array}{l}\text { AGP, Sa } 669 \\
\text { (2); Carmena } \\
\text { y Millán, } \\
\text { 2002:19; ECP, } \\
\text { 1696:4; LEP, } \\
\text { 258:4; LES, } \\
539: 4\end{array}$ \\
\hline $\begin{array}{l}22 \text { Enero } \\
1850(\mathrm{E})\end{array}$ & & & $L E P, 270: 4$ \\
\hline $\begin{array}{l}23 \text { Enero } \\
1850\left(1^{\mathrm{a}} \mathrm{REP}\right)\end{array}$ & & & $\begin{array}{l}\text { AGP, Sa } 669 \\
(1) ; E H, \\
2355: 3 ; L E P, \\
271: 4 ; \text { Subirá: } \\
24\end{array}$ \\
\hline $\begin{array}{l}25 \text { Enero } \\
1850\end{array}$ & & & $\begin{array}{l}\text { AGP, Sa } 669 \\
\text { (1); LES, } \\
552: 4 ; \text { Subirá: } \\
247\end{array}$ \\
\hline $\begin{array}{l}27 \text { Enero } \\
1850\end{array}$ & & & $\begin{array}{l}\text { AGP, Sa } 669 \\
\text { (1); LES, } \\
554: 1 ; \text { Subirá: } \\
247\end{array}$ \\
\hline $\begin{array}{l}28 \text { Enero } \\
1850\end{array}$ & & & $E H, 2360: 4$ \\
\hline
\end{tabular}




\begin{tabular}{|c|c|}
\hline $\begin{array}{l}\text { ¿29 Enero } \\
1850 ?\end{array}$ & Subirá: 247 \\
\hline $\begin{array}{l}30 \text { Enero } \\
1850\end{array}$ & $\begin{array}{l}\text { AGP, Sa } 669 \\
(1) ; \\
D O D A D M, \\
812: 4\end{array}$ \\
\hline $\begin{array}{l}8 \text { Febrero } \\
1850 \text { (SUSP) }\end{array}$ & $\begin{array}{l}E H, 2367: 3, \\
2370: 3 ; L E S, \\
562: 4\end{array}$ \\
\hline $\begin{array}{l}10 \text { Febrero } \\
1850\end{array}$ & $\begin{array}{l}\text { AGP, Sa } 669 \\
\text { (1); } E H, \\
\text { 2371:4; } \\
\text { Subirá: } 247\end{array}$ \\
\hline $\begin{array}{l}¿ 12 \text { Febrero } \\
1850 ?\end{array}$ & $\begin{array}{l}\text { AGP, Sa } 669 \\
\text { (1); Subirá: } \\
247\end{array}$ \\
\hline $\begin{array}{l}16 \text { Febrero } \\
1850\left(7^{\mathrm{a}} \mathrm{REP}\right)\end{array}$ & $\begin{array}{l}\text { AGP, Sa } 669 \\
(1) ; E H, \\
\text { 2377:4; LEP, } \\
\text { 293:4, 295:4; } \\
\text { Subirá: } 247\end{array}$ \\
\hline
\end{tabular}

\begin{tabular}{|c|c|c|c|}
\hline \multicolumn{4}{|c|}{ LA CONQUISTA DE GRANADA } \\
\hline FECHA & EDICIONES & INTÉRPRETES & FUENTES \\
\hline $\begin{array}{l}8 \text { Octubre } 1850 \\
\text { (E) }\end{array}$ & \multirow{2}{*}{$\begin{array}{l}\text {-La Conquista } \\
\text { de Granada. } \\
\text { Drama lírico de } \\
\text { Temístodes } \\
\text { Solera... puesto } \\
\text { en música... por } \\
\text { J. Emilio }\end{array}$} & $\begin{array}{l}\text { Manuela Oreiro y Lema } \\
\text { de Vega, Sofía Vela de } \\
\text { Aguirre, Rafaela } \\
\text { Ramírez, }\end{array}$ & $E C P, 1904: 4 ;$ LEP, $493: 4$ \\
\hline 10 Octubre 1850 & & $\begin{array}{l}\text { Aguirre, Rafaela } \\
\text { Ramírez, } \\
\text { Lázaro Puig (Flavio) } \\
\text { Marqués de Gáuna, Anto- } \\
\text { nio Guallart, Joaquín } \\
\text { Reguer, Francisco Calvet, } \\
\text { Cosme Algarra, Leo- } \\
\text { poldo Lopez (Carmena y } \\
\text { Millán, 2002:19-20) } \\
\text { Sofia Vela, Lema de } \\
\text { Vega, Puig (EH, 2565:3; } \\
E O, 806: 3 ; E P, 1330: 4 ; \\
L E, 1836: 3)\end{array}$ & $\begin{array}{l}\text { AGP, Sa } 669(1-2) \text {; Carmena } \\
\text { y Millán, 2002:19-20; } E C P, \\
\text { 1881:3, 1886:3; EH, 2551:3, } \\
\text { 2565:3; EO, 806:3; } \\
E P, 1330: 4 ; L E, 1836: 3 ; \\
L E, 1844: 3 ; L E P, 469: 4, \\
\text { 484:4, 495:4; LES, 770:4; } \\
\text { Subirá: } 248\end{array}$ \\
\hline
\end{tabular}




\begin{tabular}{|c|c|c|}
\hline 13 Octubre 1850 & \multirow{5}{*}{$\begin{array}{l}\quad \ldots \\
\text { Sofia Vela, Lema de } \\
\text { Vega, Puig, Reguer, Cal- } \\
\text { vet, Guallart (LEP, } \\
493: 4) \\
\quad \ldots \\
\text { ANUNCIOS CON } \\
\text { ATRIBUCIONES } \\
\text { EQUÍVOCAS DE CAN- } \\
\text { TANTES EN LAS REP- } \\
\text { RESENTACIONES: } \\
\text { Sras. Alboni, Frezzo- } \\
\text { lini y Sres. Gardoni, } \\
\text { Ronconi }(E P, 1382: 3 ; \\
L E S, 810: 4)\end{array}$} & $\begin{array}{l}\text { AGP, Sa } 669 \text { (1-2); Subirá: } \\
248\end{array}$ \\
\hline $\begin{array}{l}\text { ¿17 Octubre } \\
1850 ?\left(3^{\mathrm{a}} \mathrm{REP}\right)\end{array}$ & & LEP, 498:4 \\
\hline 29 Octubre 1850 & & $E C P, 1926: 3$ \\
\hline 30 Octubre 1850 & & AGP, Sa 669 (2); LEP, 512:4 \\
\hline 31 Octubre 185 & & $\begin{array}{l}\text { AGP, Sa } 669(1) ; E C P, \\
\text { 1926:3; EH, 2594:3; Subirá: } \\
248\end{array}$ \\
\hline
\end{tabular}

\begin{tabular}{|c|c|c|c|}
\hline \multicolumn{4}{|c|}{ LUISA MILLER } \\
\hline FECHA & $\begin{array}{l}\text { EDICIONES DE ÉPO- } \\
\text { CA }\end{array}$ & INTÉRPRETES & FUENTES \\
\hline 27 Abril 1851 & \multirow{5}{*}{$\begin{array}{l}\text {-Luisa Miller: melo- } \\
\text { drama trágico en tres } \\
\text { actos de Salvator Cam- } \\
\text { marano; música del } \\
\text { maestro Giuseppe Verdi. } \\
\text { Madrid: Aguado, } 1851^{*}\end{array}$} & \multirow{5}{*}{$\begin{array}{l}\text { Manuela Oreiro y } \\
\text { Lema de Vega, Sofía } \\
\text { Vela de Aguirre, Ra- } \\
\text { faela Ramirez, Láz- } \\
\text { aro Puig (Flavio) } \\
\text { Joaquín Reguer, } \\
\text { Francisco Calvet, } \\
\text { Gironella (EP, } \\
\text { 1451:4) }\end{array}$} & $\begin{array}{l}\text { AGP, Sa } 669(1-2) ; \\
D O D A D M, 186: 4 ; \\
D O D A D M, 187: 3 ; \\
E O, 975: 2 ; \text { Subirá: } 248\end{array}$ \\
\hline 29 Abril 1851 & & & $\begin{array}{l}\text { El Mundo Nuevo (EMN), } \\
6: 4\end{array}$ \\
\hline 30 Abril 1851 & & & $C D L T, 22: 1 ; E H, 2747: 3$ \\
\hline ¿3 Mayo $1851 ?$ & & & $L E P, 668: 3$ \\
\hline 4 Mayo 1851 & & & $\begin{array}{l}A G P, \text { Sa } 669 \text { (1-2); LEP, } \\
670: 3\end{array}$ \\
\hline \multicolumn{4}{|c|}{$\begin{array}{l}\text { * Obsérvese la edición italiana del mismo año, de la cual disponemos de un ejemplar en la } \\
\text { Biblioteca del Palacio Real: Luisa Miller: melodramma tragico in } 3 \text { atti/di S. Cammarano; } \\
\text { posto in musica dal maestro Giuseppe Verdi, alla tragica poetessa cultrice esimix delle } \\
\text { arti Belle signora Laura Beatrice mancini Nata Oliva. Milano: [s.n.], [1851?] (dall } \sqrt{I} \text {.R. } \\
\text { Stabilimento Nazionale Privilegiato di Giovanni Ricordi) }\end{array}$} \\
\hline
\end{tabular}




\section{Sobre el Autor}

Sara Navarro Lalanda: Estudió en la Universidad Autónoma de Madrid la licenciatura de Historia y Ciencias de la Música (2007). Asimismo, en el Real Conservatorio Superior de Música de Madrid obtuvo los Títulos de Profesor Superior de Lenguaje Musical (2007) y Musicología (2008). Amplia su formación con el Master oficial en Gestión de la Documentación de la Universidad Complutense de Madrid (UCM). Está en posesión del Diploma de estudios avanzados (2010) y del proyecto de tesis (mayo del 2010), centrados ambos en el estudio de la política musical de María Cristina de Borbón- Dos Sicilias. En la actualidad, disfruta de un contrato FPU del Ministerio de Educación desde enero de 2010 (AP200801081). Como resultado de sus investigaciones, ha participado en numerosos congresos destacando los congresos italianos XVIII convegno della Società Italiana di Musicologia celebrado en Génova del 21 al 23 de octubre y en el XV Colloquio di Musicologia del Saggiatore musicale celebrado del 18 al 20 de noviembre de 2011. Ha publicado en capítulos de libros como Imprenta y edición musical en España (ss. XVIII-XX), en La Natividad: arte religiosidad y tradiciones populares (Actas simposium 2009) y como redactora en Visiones del Quijote en la música del siglo XX. 